Rafael Meira Ribeiro

Wolbachia e Incompatibilidade

Citoplasmática em Anastrepha sp.1 aff.

fraterculus e A. obliqua (Diptera:

Tephritidae)

São Paulo 
Rafael Meira Ribeiro

\section{Wolbachia e Incompatibilidade \\ Citoplasmática em Anastrepha sp.1 aff. \\ fraterculus e A. obliqua (Diptera: \\ Tephritidae)}

Dissertação apresentada ao Instituto de Biociências da Universidade de São Paulo, para a obtenção de Título de Mestre em Ciências, na Área de Biologia/Genética.

Orientador(a): Prof ${ }^{a}$. Dr ${ }^{a}$. Denise Selivon Scheepmaker

São Paulo 2009 
Ribeiro, Rafael Meira

Wolbachia e Incompatibilidade

Citoplasmática em Anastrepha sp1 aff. fraterculus e $A$. obliqua (Diptera:

Tephritidae)

51 páginas

Dissertação (Mestrado) - Instituto de Biociências da Universidade de São Paulo. Departamento de Genética e Biologia Evolutiva.

1. Bactéria 2. Endossimbionte 3. Moscas-das-frutas I. Universidade de São Paulo. Instituto de Biociências. Departamento de Genética e Biologia Evolutiva.

\section{Comissão Julgadora:}

$\operatorname{Prof}(\mathrm{a}) . \operatorname{Dr}(\mathrm{a})$.

$\operatorname{Prof}(a) . \operatorname{Dr}(a)$.

Prof ${ }^{a}$. Dr. ${ }^{a}$. Denise Selivon Scheepmaker

Orientadora 
À minha família. 
Nor are new inventions of theory the only scientific events that have revolutionary impact upon the specialists in whose domain they occur. The commitments that govern normal science specify not only what sorts of entities the universe does contain, but also, by implication, those that it does not... That is why the unexpected discovery is not simply factual in its import and why the scientist's world is qualitatively transformed as well as quantitatively enriched by fundamental novelties of either fact or theory.

(Thomas S. Kuhn, The Structure of Scientific Revolution, 1962)

Ille nihil dubitat qui nullam scientiam habet.

(Pereira 111) 


\section{Agradecimentos}

À Prof. ${ }^{a}$ Dr ${ }^{a}$ Denise Selivon Scheepmaker e ao Prof. Dr. André Luiz Paranhos Perondini pelas valiosas lições acadêmicas e por terem sido muito mais que orientadores.

À Elzi pela indispensável ajuda no manejo das populações de moscas-dasfrutas e pelos momentos agradáveis durante as pausas para o almoço.

Aos amigos do Laboratório de Biologia Evolutiva e Desenvolvimento de Insetos: Roberto, Rominy e Leandro, em especial, ao último, pelo auxílio na execução de alguns protocolos.

Aos amigos de graduação: Arthur, Erika, Ricardo, Fabíola e Henrique pela companhia e pelo compartilhamento das dificuldades e outras atribulações inerentes à atividade discente.

À minha família, em especial, ao meu pai e à minha avó paterna. por terem me proporcionado suporte afetivo e financeiro.

À Denise, minha namorada, por tantos anos de paciência, planos e por todo amor do mundo em troca de outro tanto.

À família Cocchi por ter me acolhido como um dos seus, incondicionalmente.

A todo professor desta universidade que de algum modo me inspirou entusiasmo pela atividade que realiza.

À todo aquele que mesmo anonimamente contribui para e grandeza e excelência desta universidade. 
Trabalho realizado com o apoio financeiro da

FAPESP (Projeto Temático, proc. 03/02698-3) 


\section{ÍNDICE}

I. INTRODUÇÃO

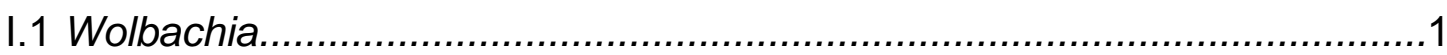

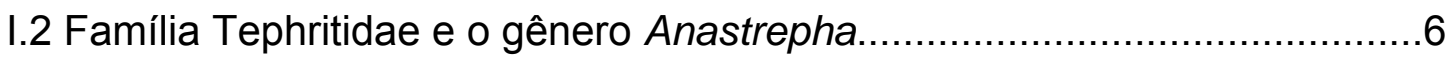

II. OBJETIVOS.

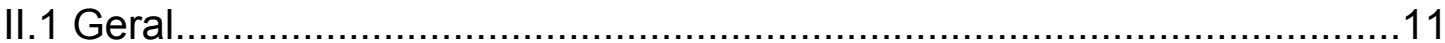

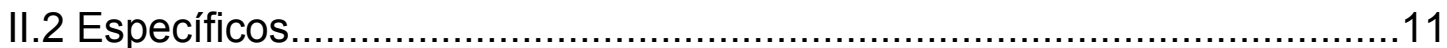

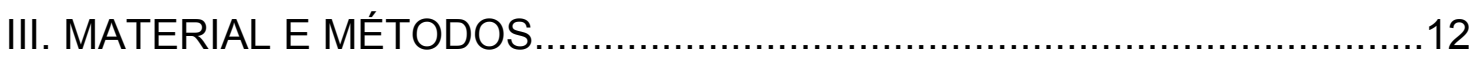

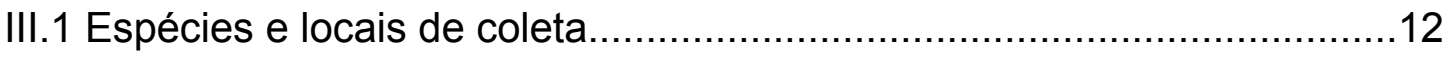

III.2 Caracterização de Wolbachia por PCR e seqüenciamento.....................12

III.3 Estimativa da densidade populacional de bactérias

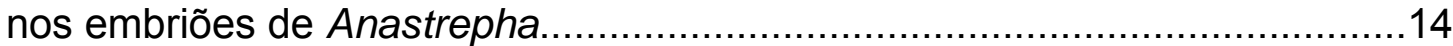

III.4 Estabelecimento de linhagens isentas (curadas) de Wolbachia por tratamento térmico e pelo antibiótico tetraciclina. 16

III.5 Análise da incompatibilidade reprodutiva entre

A. obliqua e A. sp1 16

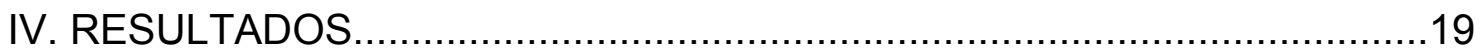

IV.1 Caracterização de Wolbachia por PCR e seqüenciamento......................19

IV.2 Estimativa da densidade populacional de bactérias

endossimbiontes nos embriões de Anastrepha..........................................19

IV.3 Eliminação de Wolbachia pela tetraciclina e por

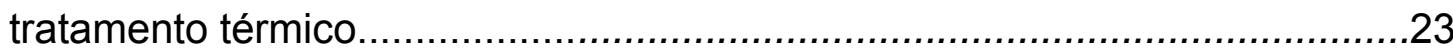

IV.4 Análise da incompatibilidade reprodutiva entre A. obliqua e A. sp.1 25

V. DISCUSSÃO

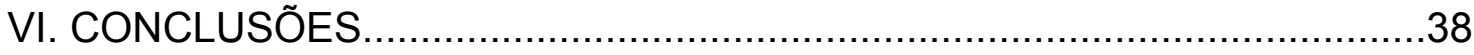

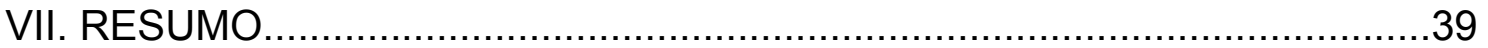


VIII. ABSTRACT.

.41

IX. REFERÊNCIAS BIBLIOGRÁFICAS.

$X$.

ANEXO. 


\section{INTRODUÇÃO}

\section{I.1 Wolbachia}

As bactérias Wolbachia são a-proteobactérias da ordem Rickettsiales gram-negativas, comumente encontradas em tecidos reprodutivos de artrópodes e são citoplasmaticamente herdadas (Werren, 1997). Essa bactéria intracelular foi primeiramente observada em tecidos reprodutivos de Culex pipiens por Hertig e Wolbach (Hertig \& Wolbach,1924 apud Werren, 1997). Posteriormente, análises baseadas na seqüência de DNAr 16S indicaram que o gênero Wolbachia forma um clado específico, mas existem controvérsias se esse clado é mono ou polifilético (O’Neill, et al., 1992, Werren, 1997). Análises moleculares demonstraram, no gênero Wolbachia, a existência de dois grandes grupos (assim denominados pela ausência de uma descrição formal das espécies) que divergem em apenas $2 \%$ na seqüência do gene DNAr 16S. Tais grupos foram denominados A e B e divergiram, provavelmente, há aproximadamente 50 milhões de anos (Werren, 1997).

Normalmente, as bactérias Wolbachia são herdadas de forma vertical através da linha materna. No entanto, essa transmissão vertical não explica o alto número de espécies infectadas por essa bactéria e, além disso, a filogenia das linhagens da Wolbachia, na maioria dos casos, não coincide com a filogenia de seus hospedeiros. Assim, numerosos trabalhos têm sugerido (rev. Werren \& O'Neill, 1997) e outros demonstrado experimentalmente (rev. Mascarenhas, 2007) que uma transmissão horizontal (transferência intertáxons) destas bactérias entre as espécies hospedeiras deve ocorrer muito freqüentemente. Panaram \& Marshall (2007), utilizando técnicas de PCR, encontraram linhagem $\mathrm{F}$ de Wolbachia, característica de nemátodes, em insetos ortópteros (Orocharis saltator e Hapithus agitator; Gryllidae: Eneopterinae). Isso indica que também pode ocorrer transmissão horizontal entre clados filogeneticamente distantes como nemátodes e artrópodes.

Recentemente, pesquisas com transinfecção lançaram uma luz sobre o mecanismo de transmissão horizontal. Em adultos de Drosophila melanogaster, observou-se que a introdução de bactérias na cavidade abdominal de fêmeas 
não infectadas levava à detecção da Wolbachia no SSCN ("Somatic Stem Cell Niche") presente no gemário (Frydman et al., 2006). É possível que as endobactérias que tem como alvo o SSCN tenham sido selecionadas por ser este um tecido com baixa taxa de divisão celular permitindo o acúmulo de bactérias no citoplasma destas células, O contato dessas células com a linhagem germinativa, favoreceria a sua transmissão vertical (Pfarr \& Hoerauf, 2006).

O seqüenciamento de wsp ("Wolbachia surface protein"), um gene altamente variável utilizado para reconhecimento e filogenia de grupos da referida endobactéria (como exemplos, Sun et al., 2007; Jamnongluk et al., 2002), demonstrou que o supergrupo A de Wolbachia pipientis pode ser dividido em oito subgrupos, e o grupo B em quatro (Zhou et al, 1998). Além disso, considera-se atualmente a existência de supergrupos C e D em alguns nemátodes, em colembolas e em um grupo $\mathrm{F}$ de térmitas (Lo et al., 2002).

No entanto, a análise de seqüência de wsp de diversas linhagens indicou a presença de quatro regiões hipervariáveis (HVR) separadas por regiões altamente conservadas. Tais análises revelaram o embaralhamento de domínios de aminoácidos dentro das HVRs, com recombinação ocorridas entre Wolbachia de supergrupos distintos encontrados em artrópodes. Isso indica a natureza em mosaico do gene wsp (Baldo et al., 2005) e a inconveniência da utilização apenas deste gene com finalidades taxonômicas (Baldo \& Werren, 2007, como exemplo de uma filogenia de supergrupos de Wolbachia, utilizando seqüenciamento de outros genes). Assim, análises moleculares filogenéticas recentes utilizando seqüenciamento dos genes $f t s Z$, groEL, gltA e dnaA mantiveram a nomenclatura dos grupos já explicitados, com diferenças no grupo $F$, que passou a ser denominado $\mathrm{H}$ e a inclusão do grupo $F$, comum a artrópodes e nemátodes. O grupo G foi detectado em em aranhas (Lo et al., 2007).

Estima-se que entre $20-70 \%$ das espécies de insetos estejam infectadas com Wolbachia e a taxa de infecção difere relativamente pouco em regiões geográficas distintas como Panamá, Grã-Bretanha e Estados Unidos (Werren \& Windsor, 2000; Jeyaprakash \& Hoy, 2000). Recentemente, amostras de insetos da Mata Atlântica foram analisadas quanto à presença de bactérias Wolbachia, indicando um nível de infecção de 45\% (Lavagnolli et al., 2005). Hilgenboecker 
et. al. (2008) estima que a proporção de espécies infectadas seja de $66 \%$ e que a taxa de infecção por espécies é geralmente ou muito alta (acima de 90\%) ou muito baixa (menor que 10\%), embora a proporção de indivíduos infectados possa variar ao longo do tempo. Por exemplo, Hoffman et al. (1998) demonstraram que a freqüência de infecção em $D$. melanogaster se mantém constante em populações de laboratório quando a densidade de larvas é pequena, mas esta taxa diminui quando há elevada densidade de larvas.

A elevada taxa de infecção de insetos por Wolbachia e o seqüenciamento do seu genoma permitiram a atual constatação da transmissão lateral ou horizontal de genes entre a endobactéria e hospedeiro. Kondo et al. (2002) observou 12 ORF's (Open Reading Frame) de Wolbachia, totalizando aproximadamente $11 \mathrm{~kb}$ no cromossomo $\mathrm{X}$ do coleóptero Callosobruchus chinensis. Nikoh et al. (2008). A localização de genes de Wolbachia na região proximal do braço curto do cromossomo $\mathrm{X}$ de $C$. chinensis, não encontrados em espécies de coleópteros filogeneticamente próximas, indica que tal fenômeno da transmissão horizontal deve ter ocorrido após o evento de especiação nesses insetos.

Em embriões de Drosophila infectados por Wolbachia, observou-se que essas bactérias se concentram no pólo posterior, local de formação das células germinativas e tal localização permite à bactéria ser transmitida verticalmente e alterar aspectos reprodutivos de seus hospedeiros (Hadfield \& Axton, 1999; Selivon et al., 2002). Entre as alterações reprodutivas nos hospedeiros destacam-se a promoção de incompatibilidade citoplasmática (Breeuwer, 1997; Keller et al., 2004), partenogênese em espécies haplodiplóides e mais raramente, em espécies diplodiplóides (Koivisto \& Braig, 2003; Werren, 1998), feminilização de machos genéticos (Rousset et al., 1992) e morte dos machos durante a embriogênese (Hurst, 1999). Além disso, em algumas espécies, a Wolbachia parece ser necessária para a oogênese (Dedeine et al., 2001). No entanto, em alguns hospedeiros, a Wolbachia parece ser uma característica neutra, já que não causa incompatibilidade citoplasmática (Charlat et al., 2004).

Utilizando como modelo embriões de D. simulans, Kose \& Karr (1995) propuseram a interação entre Wolbachia e os microtúbulos da célula hospedeira, o que explicaria a sua distribuição equitativa em direção aos pólos do fuso durante a mitose e a localização desses endossimbiontes no córtex do 
embrião durante a blastoderme, ou seja, na região do embrião organizada pelos microtúbulos.

De alguma forma, as células hospedeiras devem liberar fatores que regulam a densidade de bactérias minimizando, assim, os efeitos negativos ao hospedeiro (Mouton et al., 2003). Utilizando transfeccção da linhagem "popcorn" de Wolbachia (cujas características distintas são a sua capacidade de replicação superior às demais linhagens e a diminuição do tempo de vida de seu hospedeiro) entre D. melanogaster e D. simulans, McGraw et al. (2002) propõem que deve ocorrer uma forte seleção nos mecanismos controladores da multiplicação das bactérias devido ao sucesso reprodutivo das moscas infectadas.

A incompatibilidade citoplasmática (IC) causada por Wolbachia é classificada em unidirecional e bidirecional (Werren, 1997). Quando um espermatozóide de macho infectado fertiliza um óvulo de fêmea não-infectada, o resultado é a incompatibilidade unidirecional. Quando ocorre o contrário, ou seja, a fêmea é infectada e o macho não, o zigoto formado pela fusão desses dois gametas é viável. A incompatibilidade citoplasmática bidirecional ocorre quando machos e fêmeas são infectados com diferentes linhagens de Wolbachia. Os resultados indicam que devem existir dois "fatores" atuando na IC mediada por Wolbachia, um atuando nos machos e outro nas fêmeas (Werren, 1997).

Postula-se que durante a espermiogênese, os cromossomos paternos sofram alguma forma de "marcação" (conhecido como sistema mod) pela ação de fatores secretados pelas bactérias. Assim, para que o processo de mitose no zigoto se complete, o ovo também deve estar infectado por uma bactéria da mesma linhagem que, ao liberar um outro fator, realiza um processo de "recuperação" (conhecido como sistema rescue) dos cromossomos paternos, viabilizando a singamia e o processo reprodutivo (Bourtzis \& O’Neill, 1998). De fato, as bactérias não precisam estar em contato com os espermatócitos ou espemátides para modificá-los. Clark et al. (2008), observaram que em besouros da espécie Chelymorpha alternans e em vespas da espécie Nasonia vitripennis, a Wolbachia é encontrada abundantemente em outras camadas dos testículos, ao invés de próxima ao esperma ou nas células do cisto. Isso pode 
indicar que a modificação do pró-núcleo masculino se dá através de múltiplas membranas ou que atua a jusante na espermiogênese.

Breeuwer \& Werren (1993) propõem que a diferença de densidade de Wolbachia entre machos e fêmeas também podem causar IC. Utilizando como modelo vespas do gênero Nasonia e uma dieta misturada à tetraciclina, esses pesquisadores propõem o modelo de "dosagem bacteriana", segundo o qual o "esperma será incompatível com o ovócito quando o número de bactérias na linhagem do macho é superior ao da linhagem da fêmea". De fato, a dosagem ou densidade bacteriana pode ser estimada em populações através da contagem de bactérias nos embriões (Breeuwer \& Werren, 1993) ou através de PCR quantitativo (Sinkins et al., 1995). Estes últimos encontram diferenças de dosagens em populações incompatíveis de Aedes albopictus, segundo o "modelo de dosagem", mas não descartaram a possibilidade da incompatibilidade citoplasmática ser causada por infecção por mais de um subgrupo de Wolbachia em uma das populações.

Foi sugerido que a perda da coordenação temporal entre os pró-núcleos masculino e feminino durante a primeira mitose é a causa da incompatibilidade. Wolbachia pode gerar tal assincronia entre o material genético de origem paterna e de origem materna, segundo observado por Tram \& Sullivan (2002).

Em termos populacionais, o efeito da incompatibilidade citoplasmática é a redução do fluxo gênico entre populações (Turelli, 2000) e por isso tem sido considerado que as bactérias do gênero Wolbachia podem ter um papel relevante no processo de especiação (Werren 1998; Telschow et al., 2005ab).

Demonstrações de que essas bactérias são as responsáveis pela incompatibilidade reprodutiva foram obtidas em várias espécies onde os endossimbiontes foram eliminados pela ação de antibióticos (Breeuwer \& Werren, 1993; Hariri et al., 1998; Jiggins et al., 2001; Koukou et al., 2006) ou por tratamentos térmicos (Bourtzis \& O’Neill, 1998; Werren, 1997).

Admitindo-se a possibilidade de dois tipos de isolamento reprodutivo entre espécies relacionadas, a saber, pré-zigótico, ou pré-cópula, e pószigótico, ou pós-cópula (Dobzhansky, 1937), a incompatibilidade citoplasmática uni e bidirecional gerada pela Wolbachia estaria incluída no segundo grupo, já que gera uma diminuição da viabilidade do híbrido. Em adição à esse mecanismo, Koukou et al. (2006) demonstraram que em populações de $D$. 
melanogaster submetidas à pressões seletivas diversas, Wolbachia e/ou outras bactérias endossimbióticas incrementam também 0 isolamento reprodutivo pré-zigótico, com alterações no comportamento sexual, ou seja, através do aumento da discriminação sexual entre os indivíduos envolvidos.

\section{I.2 Família Tephritidae e o gênero Anastrepha}

Dentre os insetos infectados por Wolbachia, estão aqueles da família Tephritidae. Várias espécies dessa família são conhecidas como as verdadeiras moscas-das-frutas, uma vez que seu desenvolvimento larval ocorre em frutos. Estas moscas completam seu desenvolvimento em quatro estágios: ovo, larva, pupa e adulto. O ciclo de vida pode ser descrito da seguinte forma: há o acasalamento seguido de ovoposição no fruto; as larvas eclodem e consomem o fruto; o fruto cai para o solo onde ocorre a ecdise pupal, a metamorfose, que culmina com a emergência dos adultos; após a maturação sexual há novamente o acasalamento (Salles, 2000).

Muitas das espécies moscas-das-frutas atacam frutos de valor comercial, o que as qualifica como insetos-praga no cenário mundial. As espécies-praga restringem-se aos gêneros Anastrepha, Bactrocera, Ceratitis, Dacus, Rhagoletis e Toxotrypana (White \& Elson-Harris, 1992).

O gênero Anastrepha é endêmico da América e contém aproximadamente 200 espécies descritas, sendo que 99 ocorrem no Brasil (Zucchi, 2007). Análises morfológicas (Norrbom et al., 1999) e da região hipervariável do gene period (Barr et al., 2007) indicam que há 17 grupos infragenéricos.

Do ponto de vista econômico uma das espécies mais relevantes na América do Sul é Anastrepha fraterculus sensu lato (mosca-das-frutas Sul Americana) que utiliza uma ampla gama de frutos hospedeiros e ocorre nas Américas entre as latitudes $35^{\circ} \mathrm{N}$ e $35^{\circ} \mathrm{S}$ (Malavasi et al., 2000). O fato de terem uma enorme gama de frutos hospedeiros, ou seja, mais de 90 (Malavasi, 2000; Zucchi, 2007), pode ser um reflexo da existência de diversas espécies crípticas não reconhecidas (Selivon et al., 2004a b). A existência de extensa 
variação morfológica nas asas dessa espécie foi considerda por Stone (1942) como devida a raças geográficas. Desde então, diversos estudos sugeriram a existência de espécies crípticas, o complexo Anastrepha fraterculus (rev. Aluja, 1994, Selivon \& Perondini, 2007).Utilizando o gene mitocondrial citocromo oxidase I (COI) em 15 espécies do gênero, sendo 12 do grupo fraterculus, Smith-Caldas et al. (2001) encontraram diversas entidades de A. fraterculus em diferentes regiões do Brasil e das Américas andina e central.

A análise de 19 locos de isozimas indicou a existência de duas entidades de $A$. fraterculus, uma delas encontradas em maiores altitudes e a outra encontrada na região litorânea. Tais resultados foram confirmados por análises cromossômicas e morfométricas da asa e do ovopositor, sendo, então, caracterizadas duas espécies, $A$. sp.1 aff. fraterculus e $A$. sp.2 aff. fraterculus a seguir referidas simplificadamente como $A$. sp.1 e A. sp.2 (Selivon, 1996; Selivon et al., 2005). Foram descritas, além dessas, duas outras espécies crípticas, a primeira encontrada no litoral e planalto das regiões sul e sudeste (A. sp.3 aff. fraterculus) e a segunda encontrada em Guayaquil, Equador ( $A$. sp.4 aff. fraterculus) (Selivon, 2004a,b). A clivagem do DNA total com endonucleases de restrição, demonstrou haver padrões distintos entre $A$. sp.1, A. sp.2 e A. sp.3, sendo que o padrão da $A$. sp.3 é o mais distinto (Rocha \& Selivon, 2004).

Análises morfométricas subsequentes do acúleo, ovopositor, asas e mesonoto de amostras populacionais de $A$. fraterculus s.l. de regiões do México, Argentina, Colômbia e Brasil indicaram que há diferenças significativas nas asas e acúleo entre populações mexicanas e brasileiras (Hernández-Ortiz et al., 2004). Esses pesquisadores propõem a existência de três morfotipos: mexicano, andino (representado pela amostra colombiana) e brasileiro (incluindo as populações brasileiras e argentina).

A análise das seqüências espaçadoras ITS1 ("Internal Transcribed spacer") do DNA ribossômico, corroborou a hipótese de que há três espécies de Anastrepha fraterculus no Brasil (A. sp.1, A. sp.2 e A. sp.3) e pelo menos outra no Equador (A. sp.4). No Brasil, as amostras apresentaram $90 \%$ de similaridade na seqüência do ITS1, sendo que $A$. sp.1 apresentou maior similaridade com A. sp.2 do que ambas com A. sp.3 (Prezotto, 2008). Quando amostras da Região Neotropical, Argentina, Peru, Colombia, Guatemala e 
México e Brasil, foram consideradas para o estabelecimento das relações filogenéticas, observou-se que no clado $A$. fraterculus s.I. há a separação entre as amostras do México e Guatemala das demais e dentre estas, há tres subgrupos, o primeiro formado por amostras de Peru e Equador, outro pela amostra da Colômbia e outro formado por Brasil e Argentina. A heterogeneidade de seqüências nas amostras da Região Neotropical, indica que possivelmente existem outras espécies no complexo fraterculus (Prezotto, 2008).

O complexo fraterculus integra, juntamente com outras 27 espécies, o grupo intragenérico fraterculus. A esse grupo pertence a maioria das espécies pragas do gênero Anastrepha, as quais, em geral, são generalistas quanto à utilização de recursos. Esse é o caso de $A$. obliqua (a mosca-das-frutas das Antilhas) que tem uma ampla lista de frutos hospedeiros registrados, cerca de 70 entre espécies de Annonaceae, Bignoniaceae, Euphorbiaceae, Fabaceae, Myrtaceae e Rosaseae(White \& Elson-Harris, 1992) e além dessas, espécies de Malpighiaceae, Oxalidaceae e Combretaceae (Malavasi et al., 2000). Entretanto, essa espécie ataca preferencialmente os frutos da família Anacardiaceae, entre elas, manga, cajá, cajá-mirim, umbu, cajarana e serigüela (Zucchi, 2007). Do ponto de vista biogeográfico, A. obliqua tem distribuição similar à $A$. fraterculus, sendo a segunda espécie mais comum na maior parte das localidades onde ocorre, com exceção do sul do Caribe e Suriname (Zucchi, 2007). Do ponto de vista morfológico, é possível diferenciar entre adultos de $A$. obliqua e do complexo $A$. fraterculus pelo acúleo do ovipositor, padrão alar e do mesonoto. Os ovos de $A$. obliqua, possuem um apêndice respiratório, contendo aerópilas em sua extremidade (estruturas que permitem as trocas gasosas porque são comunicações entre o meio externo e os espaços internos do córion) e na sua base, a micrópila (orifício que permite a entrada do espermatozóide). Já os ovos das espécies caracterizadas do complexo fraterculus não apresentam o apêndice respiratório em sua extremidade ( Murillio \& Jirón, 1994; Selivon \& Perondini, 2000).

Do ponto de vista taxonômico, as espécies $A$. obliqua e as espécies do complexo fraterculus são distintas. No entanto, elas são capazes de copular e gerar híbridos férteis em condições de laboratório, embora não seja possível afirmar a ocorrência de hibridação na natureza (Santos et al., 2001), apesar da 
ampla área de coexistência entre ambas (Malavasi et al., 2000). Segundo Santos et al. (2001), há maior isolamento entre $A$. fraterculus e $A$. obliqua e entre $A$. sororcula e $A$. obliqua, do que entre $A$. fraterculus e $A$. sororcula, indicando uma possível maior proximidade filogenética entre estas do que com A. obliqua.

Estudos sobre a progênie híbrida obtida dos cruzamentos entre $A$. obliqua e as espécies do complexo fraterculus indicaram que esta é variável de acordo com os diferentes arranjos dos tipos parentais, de acordo com a regra de Haldane (1922), segundo a qual "quando um dos sexos dos híbridos F1 resultantes do cruzamento entre duas espécies é estéril ou inviável, este é quase sempre o heterogamético". Por exemplo, o cruzamento entre A. sp.2 aff. fraterculus e $A$. obliqua produz apenas fêmeas ou não produz descendentes, dependendo se a fêmea parental é sp.2 ou obliqua respectivamente, enquanto que o cruzamento entre $A$. sp. 1 e $A$. obliqua produz machos e fêmeas, ou só fêmeas, a depender da fêmea parental ser obliqua ou sp.1, respectivamente (Santos et al. 2001). Reduções nas taxas de eclosão de larvas e desvios na proporção sexual da progênie adulta foram previamente observados em cruzamentos entre A. sp.1 e A. sp.2 (Selivon et al. 1999, 2005). Esses autores invocaram um possível efeito causado por Wolbachia para explicar esses resultados, uma vez que a infecção em A. sp.2 já era conhecida (Selivon et al. 2002).

A ocorrência de Wolbachia está descrita em várias espécies de Anastrepha, A. sp.1, A. sp.2, A. sp.3, A. sp.4, A. amita, A. distinta, A. bistrigata, A. grandis, A. macrura, A. montei, A. obliqua, A. pickeli, A. serpentina, A. sororcula, A. striata e A. turpinae (Werren et al., 1995; Selivon et al., 2002; Coscrato, 2006; Mascarenhas, 2007) e também em outros gêneros de moscasdas-frutas de outros gêneros, Rhagoletis (Riegler \& Staufer 2002), Bactrocera (Kittayapong et al., 2000; Jamnongluk et al., 2002; Sun et al., 2007) e Ceratitis capitata (Rocha et al., 2005).

O fenômeno de incompatibilidade citoplasmática relacionado com a presença de Wolbachia foi demonstrado em Rhagoletis cerasi (Riegler \& Staufer 2002) e em C. capitata (Zabalou et al., 2004). Tais resultados levaram a perspectiva de utilização desses endossimbiontes em técnicas de controle desses insetos-praga, similares aos princípios do TIE (Técnica do Inseto 
Estéril), onde a redução populacional seria feita pela liberação de machos infectados com linhagens de bactérias distintas das populações naturais (ou simplesmente machos infectados em relação às populações naturalmente isentas de Wolbachia) em lugar de machos esterelizados por radiação (Beard et al., 1993; Zabalou et al., 2004).

A presença de Wolbachia em moscas-das-frutas aliada a possibilidade de obtenção de progênie híbrida entre $A$. obliqua e $A$. sp.1 aff. fraterculus em condições de laboratório, indicam ser esse um excelente material biológico para avaliar-se alterações reprodutivas associadas à presença dessa bactéria. 


\section{OBJETIVOS}

\section{II.1 Geral}

- Avaliar o efeito da bactéria Wolbachia em aspectos reprodutivos nas moscas-das-frutas A. obliqua e A. sp.1 aff. fraterculus.

\section{II.2 Específicos}

- Caracterizar as linhagens de Wolbachia presentes em A.sp.1 aff. fraterculus e A. obliqua;

- Analisar a densidade populacional das bactérias em amostras de embriões de $A$. obliqua e A. sp.1;

- Obter linhagens de A. obliqua e A. sp.1 isentas (curadas) de Wolbachia por tratamento térmico ou por antibiótico;

- Descrever os resultados de cruzamentos envolvendo as espécies $A$. obliqua e A. sp.1 aff fraterculus quanto às taxas de eclosão e da emergência e proporção sexual da progênie adulta;

- Verificar o tipo de progênie obtida em cruzamentos intra-específicos de A. obiqua e de A. sp.1 infectadas por Wolbachia;

- Verificar o tipo de progênie obtida em cruzamentos intra-específicos de A. obliqua e de A. sp.1 isentas (curadas) de Wolbachia;

- Verificar o tipo de progênies obtidas em cruzamentos interespecíficos de A. obliqua e de A. sp.1 curadas ou infectadas por Wolbachia; 


\section{MATERIAL E MÉTODOS}

\section{III.1 Espécies e locais de coleta}

As populações de $A$. sp. 1 aff. fraterculus foram estabelecidas a partir de indivíduos coletados em goiabas (Psidium guajava) no município de Santa Isabel, SP $\left(23^{\circ} 18^{\prime} \mathrm{S} / 46^{\circ} 14^{\prime} \mathrm{W}\right)$.

As populações de $A$. obliqua foram estabelecidas a partir de indivíduos coletados em carambola (Averrhoa carambolae) no município de Vargem Grande do Sul, SP $\left(21^{\circ} 50^{\prime} \mathrm{S} / 46^{\circ} 53^{\prime} \mathrm{W}\right)$

Os frutos infestados foram trazidos ao laboratório, as pupas coletadas e mantidas até a emergência do adultos por metodologia estabelecida anteriormente (Selivon, 1996). Com esses adultos foram estabelecidas colônias em caixas de população de $30 \times 30 \times 40 \mathrm{~cm}$, mantidas em sala com controle de temperatura a $25^{\circ} \mathrm{C}$, umidade relativa de $70 \pm 5 \%$, fotoperíodo natural e dieta preparada com os seguintes ingredientes: $10 \mathrm{ml}$ de mel, $30 \mathrm{ml}$ de hidrolisado de proteína de milho, 0,5g de Levemil $\circledast$, $6 \mathrm{~g}$ de Levedo de cerveja, 0,5 de Sustagem ${ }^{\circledR}, 25 \mathrm{~g}$ de açúcar mascavo e $45 \mathrm{~g}$ de açúcar branco. A água foi fornecida através de um tira de esponja de celulose (Chamex®) que permanece constante embebida por ficar inserida em um recipiente com água. Para a oviposição, foram fornecidos frutos, mamão para Anastrepha sp1 aff. fraterculus e manga para $A$. obliqua. Uma semana depois, os frutos eram retirados e acondicionados em recipientes com vermiculita até a obtenção de pupas. Estas foram transferidas para as caixas acrílicas onde emergiram e permaneceram os adultos (Selivon, 1996).

\section{III.2 Caracterização de Wolbachia por PCR e seqüenciamento}

O DNA total foi extraído segundo protocolo adaptado de Jowett (1986), o qual é brevemente descrito a seguir. Indivíduos adultos armazenados em 
nitrogênio líquido, foram colocados individualmente em tubos de polipropileno de $1,5 \mathrm{ml}$ em $200 \mu \mathrm{l}$ de solução de homogeneização [Tris_HCl $10 \mathrm{mM}(\mathrm{pH}=7,5)$, $\mathrm{NaCl} 60 \mathrm{mM}$, EDTA $50 \mathrm{mM}$ ] e após maceração, foi acrescentado o mesmo volume de solução de lise [SDS 1,25\%, Tris-HCl 0,3M ( $\mathrm{pH}=9,0)$, EDTA 0,1M, sacarose $5 \%$ ]. Foram adicionados $2 \mu \mathrm{l}$ de Proteinase $\mathrm{K}(100 \mu \mathrm{g} / \mathrm{ml})$, seguindo-se incubação por uma hora a $65^{\circ} \mathrm{C}$. Após esses procedimentos, foram acrescentados $120 \mu \mathrm{l}$ de acetato de potássio $8 \mathrm{M}$, seguindo-se incubação em gelo por 45 minutos. Após esse procedimento, o material foi centrifugado ( $10 \mathrm{~min}$, a $20000 \mathrm{G}$, a $4^{\circ} \mathrm{C}$ ), seguindo-se à precipitação com etanol absoluto e centrifugação por 5 min a $20000 \mathrm{G}$, a temperatura ambiente para precipitação do DNA. O precipitado foi lavado em etanol $70 \%$ e, após secagem, a solução final foi ressuspendida em $30 \mu \mathrm{l}$ de TE [10mM Tris- $\mathrm{HCl}, \mathrm{pH}=8,0) ; 1 \mathrm{mM}$ EDTA] e armazenada a $-20^{\circ} \mathrm{C}$. Para eliminar o RNA, as amostras foram tratadas com RNase (Ribonuclease A, Sigma) a uma concentração final de $100 \mu \mathrm{g} / \mathrm{ml}$, durante uma hora, a $37^{\circ} \mathrm{C}$. Para atestar a presença de Wolbachia, foram feitas reações de $\mathrm{PCR}$, utilizando-se os iniciadores específicos de Wolbachia wsp 81F (5'TGGTCCAATAAGTGATGAAGAAAC3') e wsp 691R (5'AAAAATTAAACGCTACTCCA3') da região do gene wsp codificador de uma proteína de membrana destas bactérias (Zhou et al., 1998). Nos casos negativos, as mesmas amostras de DNA foram testadas para amplificação de uma porção do gene ribossômico eucariótico 28S rDNA, utilizando-se os iniciadores 28SF3633 (5'TACCGTGAGGGAAAGTTGAAA3') e $28 S R 4076$ (5'AGACTCCTTGGTCCGTGTTTT3') com o intuito de testar a qualidade do DNA utilizado para a deteç̧ão das bactérias por PCR. Caso essa amplificação também fosse negativa, foram testadas outras concentrações de DNA para amplificação, conforme descrito por Werren et al. (1995). Caso fosse necessário, novas extrações de DNA foram feitas para que fosse excluída a possibilidade de que a ausência de fragmentos amplificados fosse devido a uma amostra de DNA degradado. As reações de PCR ("Polymerase Chain Reactions") tiveram volume final de $20 \mu \mathrm{l}$ com as seguintes proporções: $13,25 \mu \mathrm{l}$ de $\mathrm{H}_{2} \mathrm{O}, 2 \mu \mathrm{l}$ de Tampão de Reação 10x (BIOTOOLS), 0,5 $\mu$ de dNTPs (10mM), $0,5 \mu \mathrm{l}$ de cada iniciador $(20 \mu \mathrm{m})$ e 0,5 unidades de polimerase de DNA (Taq) (BIOTOOLS) e 3,0 $\mu$ l de amostra. Para as amplificações foram utilizada a configuração: $94^{\circ} \mathrm{C} 1 \mathrm{~min}, 55^{\circ} \mathrm{C} 1 \mathrm{~min}$ e $72^{\circ} \mathrm{C} 1 \mathrm{~min}$ por 35 ciclos e para a 
amplificação do $28 \mathrm{~S}$ rDNA eucariótico a configuração $94^{\circ} \mathrm{C} 2 \mathrm{~min}, 38$ ciclos de $94^{\circ} \mathrm{C} 30 \mathrm{~s}, 58^{\circ} \mathrm{C}$ por $50 \mathrm{~s} \mathrm{e} 72^{\circ} \mathrm{C}$ por $1 \mathrm{~m} 30 \mathrm{~s}$, e $72^{\circ} \mathrm{C} 10 \mathrm{~min}$ (Werren \& Windsor, 2000).

Para determinar a presença e o tamanho do fragmento amplificado, uma alíquota de cada amostra foi analisada em gel de agarose a $1 \%$ em tampão TAE. A eletroforese foi realizada em cubas horizontais com solução tampão de corrida TAE 1x sob corrente elétrica alternada a uma tensão de $0,6 \mathrm{~A}, 5 \mathrm{~V} / \mathrm{cm}$ de gel. O gel foi corado com brometo de etídio a $5 \mu \mathrm{g} / \mathrm{ml}$, examinado sob luz ultravioleta e fotografado com câmera digital.

Os fragmentos de wsp amplificados foram purificados seguindo 0 protocolo Perfect Gel Cleanup $\AA$ (Eppendorf, Hamburg, Alemanha) e seqüenciados em seqüenciador automático $A B I 377$ (Applied Biosystems). Reações de seqüenciamento foram montadas seguindo as seguintes

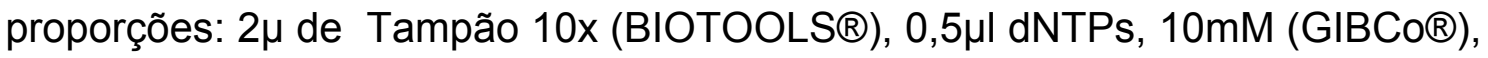
$0,5 \mu \mathrm{l}$ de iniciador $20 \mu \mathrm{M}$ ( $81 \mathrm{~F}$ ou $691 \mathrm{R}$ ), 0,5 unidade de polimerase de DNA (Taq) (BIOTOOLS $\otimes$ ), $3 \mu$ l de amostra de DNA e $\mathrm{H}_{2} \mathrm{O}$ até $20 \mu \mathrm{l}$.

As seqüências obtidas foram analisadas através do Bioedit $\circledast$ e as seqüências consenso comparadas com sequências de Wolbachia de depositadas no NCBI.

\section{III.3 Estimativa da densidade populacional de bactérias nos embriões de Anastrepha}

Os ovos e embriões de A. sp.1 e A. obliqua, foram obtidos por técnica já estabelecida no laboratório (Selivon et al., 1996). Para as fêmeas depositarem os ovos, foram fornecidas semi-esferas de agar a $2 \%$ coradas por anilina vermelha e envoltas por Parafilm $®$ "M" . Os ovos foram retirados das semiesferas e transferidos para um lâmina escavada contendo solução de hipoclorito de sódio a 3\% para a remoção do córion. Para fixação, os ovos foram submetidos a duas lavagens com PBT e transferidos para uma solução de $370 \mu \mathrm{l}$ de paraformaldeído $4 \%$ e $370 \mu \mathrm{l}$ de heptano, sob agitação leve por 20 min. Em seguida, foi retirado 1/3 da solução e acrescentados $500 \mu \mathrm{l}$ de heptano 
e 500 $\mu \mathrm{l}$ de metanol sob agitação forte por $1 \mathrm{~min}$. Após esse procedimento, foram realizadas duas lavagens com metanol. Caso ao final desse processo a membrana vitelínica não tivesse sido removida, foi retirada manualmente utilizando fita adesiva dupla-face (Wieschaus \& Nüsslein-Volhard, 1986). Os embriões foram então reidratados em etanol $50 \%$, etanol $25 \%$ e água destilada, lavados com PBT e, então, corados pelo fluorocromo DAPI (2,6diaminofenolindole) por 10min e por fim, lavados em PBS por $1 \mathrm{~min}$ (Selivon et al., 2002).

Os embriões corados foram montados entre lâmina e lamínula para análise em microscópio equipado com epifluorescência (OLYMPUS BX60®), utilizando-se o filtro adequado para a visualização das bactérias coradas por DAPI. As imagens foram digitalizadas por uma câmara CCD (Leica DC100®) acoplada ao microscópio.

O grau de infecção foi estimado através da contagem do número de bactérias na região cortical dos embriões em estágios iniciais do desenvolvimento (divisões intravitelínicas). Essa análise foi feita utilizando-se o programa AdobePhotoshop $®$ ajustando-se, às imagens dos embriões, uma grade com quadrados de $10 \mu \mathrm{m}$ de lado. Foram analisados cinco embriões de cada espécie e em cada um, foram amostrados cinco quadrados cujas posições foram determinadas "a priori" ao longo da linha mediana lateral dos embriões, estando o primeiro próximo ao pólo anterior, três ao longo do eixo A/P e o último próximo ao pólo posterior. A densidade populacional geral das bactérias por embrião, foi estimada pela média dos valores das cinco contagens por embrião e expressa como o número de bactérias por $100 \mu \mathrm{m}^{2}$. Foram contabilizadas apenas as bactérias presentes no plano focal logo abaixo da superfície do embrião, dada a impossibilidade de contar as bactérias que estão imersas no interior do vitelo. Assim, o método fornece um índice relativo da densidade de bactérias por embrião (Breeuwer \& Werren, 1993; Selivon et al., 2002). Os dados obtidos foram submetidos à uma análise de Regressão Múltipla entre a densidade de bactérias (por $100 \mu m^{2}$ ) em cada área contra a localização ao longo do eixo A/P dos embriões, utilizando-se o programa Statistica 6.0 (Statsoft Inc.). 


\section{III.4. Estabelecimento de linhagens isentas (curadas) de Wolbachia por tratamento térmico e pelo antibiótico tetraciclina}

A eliminação de bactérias foi testada por dois métodos, ambos aplicados as colônias de $A$. sp.1 e de $A$. obliqua do laboratório.

Para tratamento pela temperatura, as pupas foram colocadas em caixas de plástico contendo vermiculita e mantidas até o momento da emergência dos adultos, em estufa cuja temperatura fora previamente fixada em $30^{\circ} \mathrm{C}$, cuidado tendo sido tomado para evitar-se a dessecação. Após a emergência, os adultos foram separados em caixas de população $(15 \times 15 \times 20 \mathrm{~cm})$ e mantidos em sala com temperatura, umidade e fotoperíodo controlados, como acima descrito (Pires, 2005)

Concomitantemente, outros lotes de pupas foram isoladas de modo similar e mantidas até o momento da emergência dos adultos em sala com condições controladas. Logo após a emergência dos adultos, iniciou-se o tratamento com o antibiótico tetraciclina que foi administrado através da alimentação. A dieta, rotineiramente utilizada na manutenção das colônias foi acrescida do antibiótico a 1\% (Breeuwer \& Werren, 1993) e fornecida por uma semana, sendo trocada a cada dois dias.

Cada método foi avaliado quanto a capacidade de eliminar a Wolbachia de seu hospedeiro, através de reações de PCR utilizando os iniciadores do gene wsp 81F e wsp 691R (descritos no item III.2). O método que apresentou maior eficiência foi utilizado para obtenção das linhagens isentas de Wolbachia e os adultos curados foram imediatamente utilizados nos cruzamentos para os testes de incompatibilidade reprodutiva entre a $A$. sp.1 e $A$. obliqua.

\section{III.5. Análise da incompatibilidade reprodutiva entre $A$. obliqua e $A$. sp1}

As análises da incompatibilidade entre $A$. sp.1 e $A$. obliqua foram feitas utilizando-se pequenas caixas de população, $15 \times 15 \times 25 \mathrm{~cm}$, contendo de 7 a 15 casais cada uma (Selivon et al., 2005) e mantidas sob condições 
controladas, como acima descrito. Foram feitos cruzamentos intra e interespecíficos tendo sido utilizados adultos infectados e outros derivados das pupas submetidas ao tratamento térmico, como descrito nas Tabelas I e II.

Tabela I - Cruzamentos intra-específicos realizados com A. sp.1 aff. fraterculus e A. obliqua

\begin{tabular}{|c|c|c|}
\hline Cruzamentos & i A. obliqua x $\widehat{\wedge}$ A. obliqua & q A. sp.1 x ${ }^{\wedge}$ A. sp.1 \\
\hline 1 & Infectado $\times$ Infectado & Infectado $\times$ Infectado \\
\hline 2 & Tratado $\times$ Tratado & Tratado $\times$ Tratado \\
\hline 3 & Infectado $\times$ Tratado & Infectado $\times$ Tratado \\
\hline 4 & Tratado $\times$ Infectado & Tratado $\times$ Infectado \\
\hline
\end{tabular}

Tabela II - Cruzamentos interespecíficos realizados entre A. sp.1 aff. fraterculus e A. obliqua

\begin{tabular}{|l|l|l|}
\hline Cruzamentos & + A. obliqua x ô A.sp.1 & + A. sp.1 x ô A.obliqua \\
\hline 1 & Infectado $\times$ Infectado & Infectado $\times$ Infectado \\
\hline 2 & Infectado $\times$ Tratado & Infectado $\times$ Tratado \\
\hline 3 & Tratado $\times$ Infectado & Tratado $\times$ Infectado \\
\hline 4 & Tratado $\times$ Tratado & Tratado $\times$ Tratado \\
\hline
\end{tabular}

Para cada cruzamento, nas progênies foram avaliadas a taxa de eclosão das larvas e a taxa de emergência e a proporção sexual da progênie adulta.

Estas análises foram feitas segundo a metodologia descrita em Selivon et al. (2005), a qual é sumariamente descrita a seguir. Para a coleta de ovos, foram disponibilizadas em cada caixa de população experimental, semi-esferas de agar a $2 \%$, coloridas com anilina vermelha e revestidas por Parafilm® "M" (ver item 3). Os ovos foram retirados das semi-esferas e transferidos para uma placa de Petri, contendo uma camada de agar a $1 \%$ e mantidos a temperatura de $25^{\circ} \mathrm{C}$. Cada placa foi monitorada por seis dias e as eclosões registradas. A 
taxa de eclosão foi expressa como o número de larvas eclodidas do número de ovos amostrados.

Concomitantemente, foram deixados frutos nas caixas de população (mamão ou manga, dependendo se a fêmea era $A$. sp1 aff. fraterculus ou $A$. obliqua, respectivamente) para a posterior obtenção dos adultos. Pupas foram coletadas e mantidas até a emergência dos adultos. Após a emergência, os adultos foram separados por sexo e seu número contado. Desta forma, foram obtidas as taxas de emergência (número de adultos a partir das pupas amostradas) e a proporção sexual. Os dados obtidos das taxas de eclosão dos diferentes cruzamentos foram analisados por testes $\chi^{2}$ em Tabelas de Contingência e as proporções sexuais da progênies adulta por $\chi^{2}$, ambos com correção de Yates, utilizando-se o programa Statistica 6.0 (Statsoft Inc.) 


\section{RESULTADOS}

\section{IV.1 Caracterização de Wolbachia por PCR e seqüenciamento}

A amplificação do gene wsp através de reações de PCR gerou fragmentos de tamanho entre 500 e 600 pb (Fig. 1). Tais fragmentos indicaram a presença de Wolbachia, tanto em machos quanto em fêmeas, nas populações de $A$. obliqua e $A$. sp1 aff fraterculus.

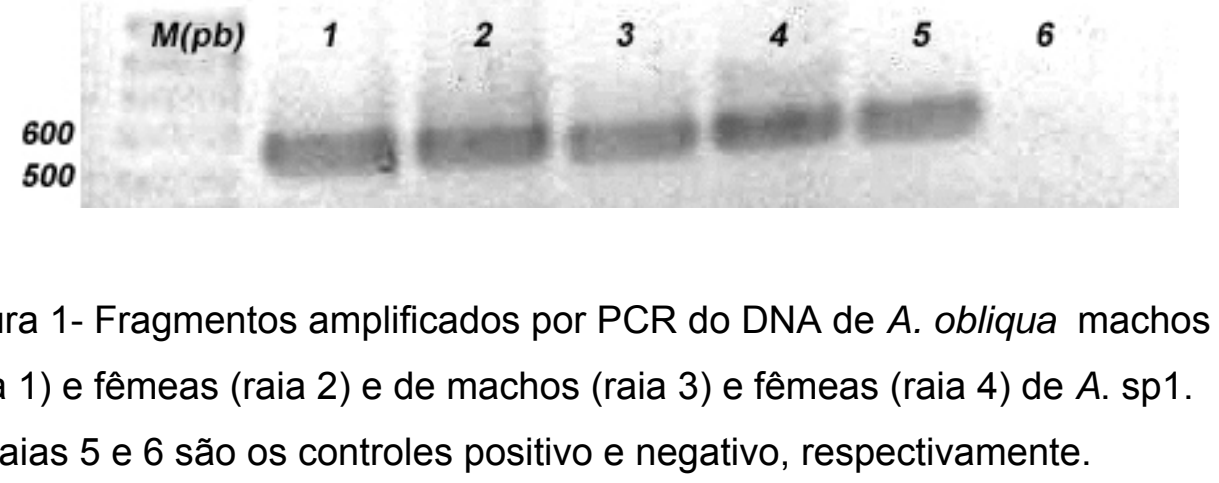

As amostras de wsp foram seqüenciadas com o intuito de identificar a linhagem de Wolbachia que infecta as populações das duas espécies de Anastrepha. Reações de seqüenciamento demonstraram que as seqüências consenso obtidas de amostras de DNA de machos e fêmeas de $A$. sp1 e de $A$. obliqua, apresentaram 0,998 de similaridade com o gene wsp da linhagem Au de Wolbachia de Drosophila simulans (acesso no GenBank número AF290891, Charlat et al, 2004). As seqüências estão mostradas no Anexo.

\section{IV.2. Estimativa da densidade populacional de bactérias endossimbiontes nos embriões de Anastrepha}

A análise de embriões fixados e corados pelo DAPI mostrou a presença de bactérias nas populações de $A$. sp1 e A. obliqua (Fig. 2) e pode-se 

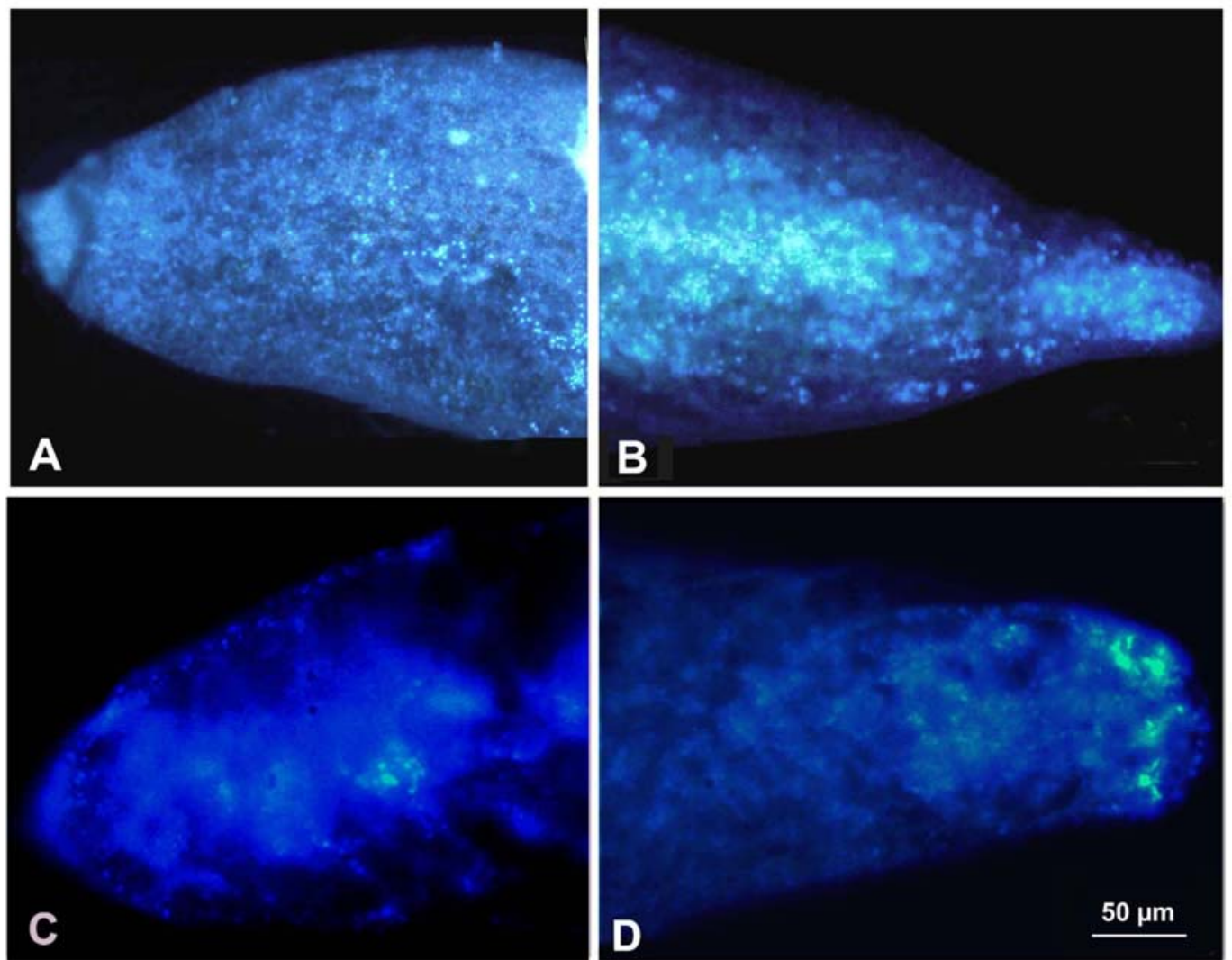

Figura 2: Fotomicrografia de fluorescência de embriões de $A$. sp.1 (A,B) e de A. obliqua $(C, D)$ corados pelo DAPI. Note-se que as bactérias (pontos brilhantes) são menos freqüentes nas extremidades anteriores ( $A$ e $C$ ) que nas extremidades posteriores ( $B$ e $D$ ) dos embriões. 
notar que existe, aparentemente, uma maior concentração de endossimbiontes na extremidade posterior do embrião.

Com o intuito de avaliar se essa concentração diferencial das bactérias é real e um fato generalizado entre os embriões das duas espécies de moscasdas-frutas, foi feita uma análise do número de bactérias por unidade de área ao longo do eixo antero-posterior dos embriões.

A densidade populacional das bactérias, estimada em amostras de cinco embriões de cada espécie hospedeira, em cinco áreas de $100 \mu \mathrm{m}^{2}$ distribuídas ao longo do eixo antero-posterior dos embriões, estão lançadas em gráficos na Figura 3. A densidade média geral (expressa por $100 \mu \mathrm{m}^{2}$ ) dos cinco embriões de cada espécies, foi de 19,8 \pm 21.6 para $A$. sp.1 e de 13,4 $\pm 11,2$ para $A$. obiqua. Como se pode observar na Figura 3, existe uma tendência de decréscimo na densidade do pólo posterior dos embriões para a extremidade anterior e que, nessas amostras, existe menor dispersão dos valores em cada área entre os embriões de A.obliqua que entre os embriões de $A$. sp.1. Realmente, uma análise de regressão múltipla mostrou que existe uma correlação significativa entre a densidade populacional de bactérias e as regiões ao longo do eixo A/P dos embriões, decrescendo do pólo posterior para $\mathrm{o}$ anterior, tanto em $A$. obliqua $(\mathrm{R}=0,798$, g.l. $=1,23 ; \mathrm{F}=40,36 ; \mathrm{P}<0.001)$ como para $A$. sp.1 ( $\mathrm{R}=0,499 ;$ g.l. =1, 23; $\mathrm{F}=5,81 ; \mathrm{P}<0.024)$. O teste também indicou que os coeficientes de regressão (b) são significativos em $A$. obliqua (b $=-6,48$, g.I. = 23; $\mathrm{t}=-6,35 ; \mathrm{P}<0.001)$ e em $A$. sp.1 $(\mathrm{b}=-6,74 ;$ g.l. $=23 ; \mathrm{t}=-2,41$; $\mathrm{P}=0,024)$, como mostra as retas traçadas na Figura 3. 

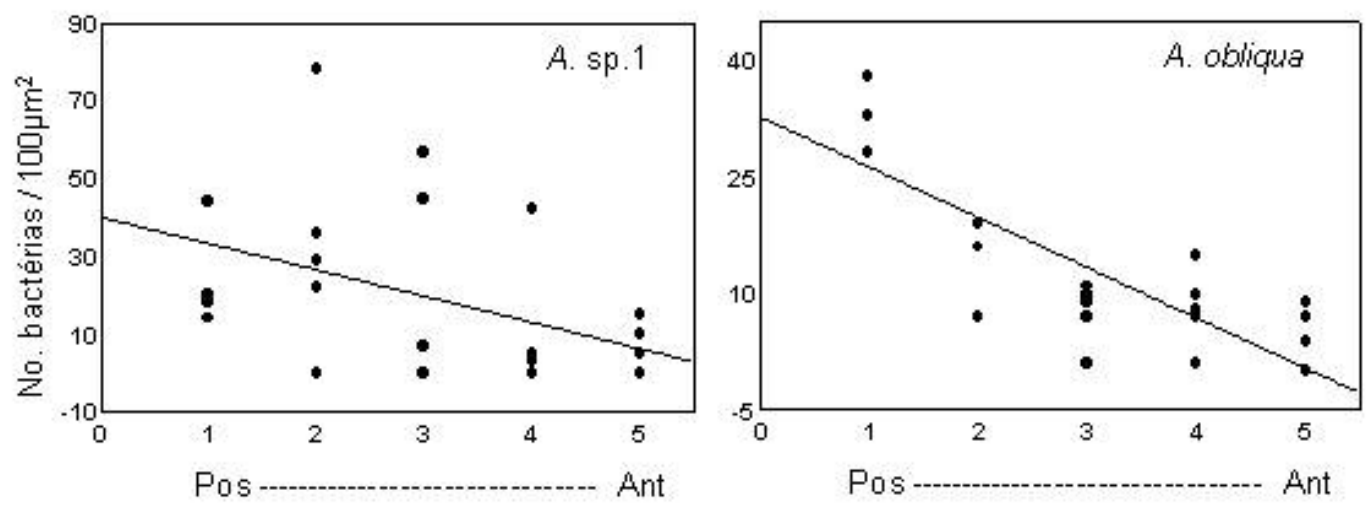

Posição no eixo antero-posterior

Figura 3. Correlaçôes entre a densidade da populaçẫo de bactérias em áreas de $100 \mu \mathrm{m}^{2}$ e a localizaçâo dessas áreas ao longo do eixo longitu dinal do embriẫo. As retas de regressão foram traçadas por an álise de regressão múltipla, sp.1: $Y=40,02-6,74 X ; A$. obliqua: $Y=32,8-6,48 X$.

Pos = pólo posterior; $\mathrm{Ant}=$ pólo anterior . 


\section{IV.3. Eliminação de Wolbachia pela tetraciclina e por tratamento térmico}

Amostras de DNA extraídas de adultos tratados com tetraciclina ou pelo tratamento térmico $\left(30^{\circ} \mathrm{C}\right)$ foram utilizadas para duas reações de PCR, a primeira com iniciadores para a amplificação do gene ribossômico eucariótico 285 e a segunda, com iniciadores do gene wsp da Wolbachia. A primeira amplificação atesta a qualidade do DNA extraído evitando falsos resultados negativos e a segunda, atesta a presença de Wolbachia.

O tratamento com tetraciclina a $1 \%$ mostrou-se pouco eficiente para a eliminação de Wolbachia de seus hospedeiros. Das cinco amostras de DNA extraídas de indivíduos tratados, apenas em uma a sequência do gene wsp não foi detectada, ou seja, em apenas um indivíduo, a Wolbachia foi eliminada pelo antibiótico (Fig. 4, raia 2). A amplificação do gene $28 \mathrm{~S}$ em todas as amostras indica que a ausência dessa sequência não é um falso negativo.

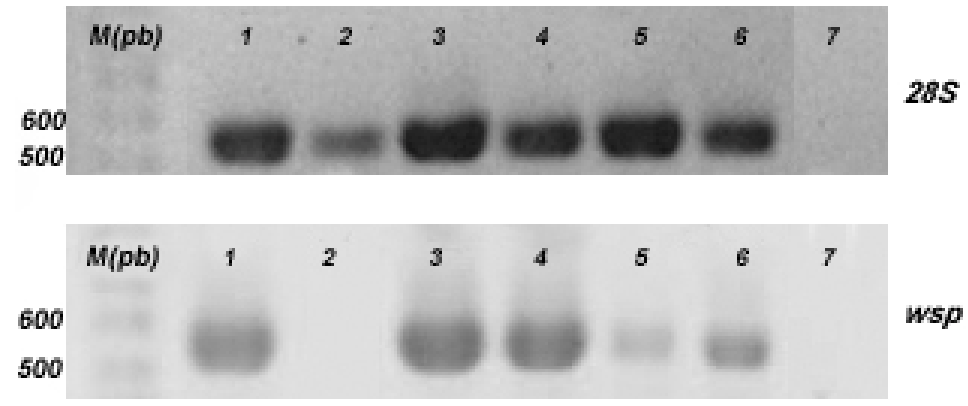

Figura 4- Fragmentos amplificados por PCR de DNA extraídos de moscas tratadas com tetraciclina a $1 \%$. Note a ausência de fragmento de wsp apenas na raia 2. As raias 6 e 7 são os controles positivo e negativo, respectivamente. 


\section{Tratamento térmico}

A taxa de emergência e a proporção sexual entre os adultos que se desenvolveram a partir de pupas tratadas a $30^{\circ} \mathrm{C}$ foram comparadas com dados de amostras de cruzamentos controles mantidos a $25^{\circ} \mathrm{C}$.

A Tabela III mostra os dados para as amostras do tratamento térmico e os dados dos cruzamentos controle encontram-se na Tabela IV. Como se pode verificar, o tratamento térmico das pupas de $A$. obliqua, reduziu a taxa de emergência dos adultos de $61,7 \%$ no controle, para $31,2 \%$, enquanto que a redução foi de $64,4 \%$ para $43,5 \%$ em $A$. sp. 1 .

O tratamento térmico, no entanto, não alterou a proporção sexual entre os adultos de ambas as espécies, pois a proporção não se desviou significativamente do 1:1 esperado, como mostram os testes das Tabelas III e IV. Assim, o tratamento térmico que elimina as bactérias induz mortalidade nas pupas, mas afeta similarmente pupas de machos quanto de fêmeas.

Tabela III - Taxas de emergência e proporção sexual de indivíduos de $A$. sp.1 e A. obliqua emergidos em estufa a $30^{\circ} \mathrm{C}$

\begin{tabular}{|c|c|c|c|c|c|c|c|c|c|}
\hline \multirow{3}{*}{ Espécie } & \multicolumn{3}{|c|}{ Emergência } & \multicolumn{6}{|c|}{ Proporção Sexual } \\
\hline & \multirow[b]{2}{*}{$\mathrm{N}$} & \multirow[b]{2}{*}{$\%$} & \multirow[b]{2}{*}{ total } & \multicolumn{2}{|c|}{ Machos } & \multicolumn{2}{|c|}{ Fêmeas } & \multicolumn{2}{|c|}{$\mathrm{X}^{\underline{2}}$ (Yates) } \\
\hline & & & & $\mathrm{N}$ & $\%$ & $\mathrm{~N}$ & $\%$ & Valor & $\mathrm{P}$ \\
\hline A. obliqua & 890 & 31,2 & 278 & 131 & 47,1 & 147 & 52,9 & 0,81 & ns \\
\hline A. sp1 & 230 & 43,5 & 100 & 52 & 52,0 & 48 & 48,0 & 0,09 & ns \\
\hline
\end{tabular}

ns: não significativo $(P>0,05)$

O DNA de oito indivíduos adultos, que se desenvolveram de pupas tratadas a $30^{\circ} \mathrm{C}$, foi extraído e alíquotas foram amplificadas por PCR. Como demonstra a Fig.3, apenas em uma das amostras o PCR do gene wsp apresentou o fragmento amplificado, ou seja, que apenas em uma amostra (raia 6) havia indício de que a Wolbachia não fora eliminada. A amplificação do 
gene 28S dessas amostras atesta a qualidade do DNA extraído e da reação de PCR.

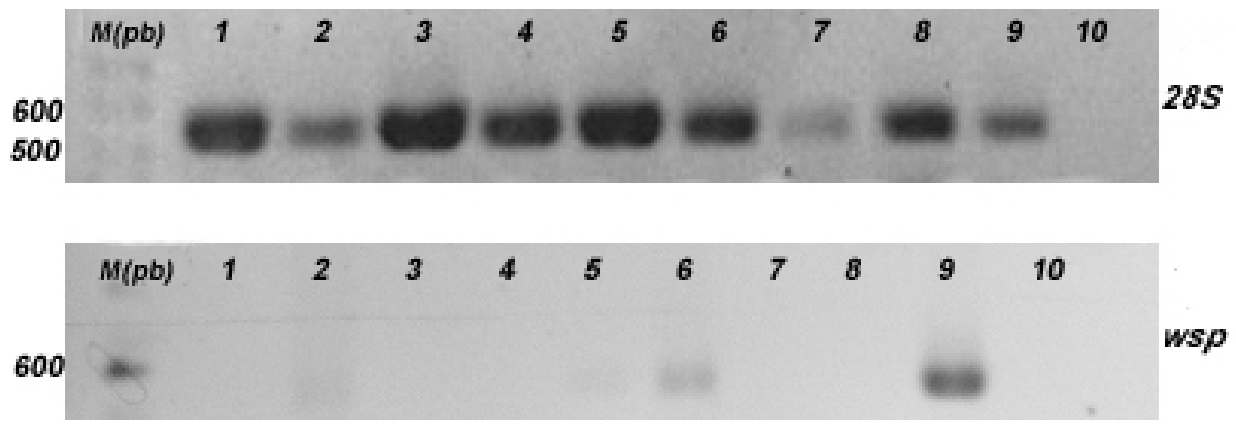

Figura 5- Fragmentos amplificados por PCR de DNA extraídos de adultos que se desenvolveram de pupas tratadas com calor $\left(30^{\circ} \mathrm{C}\right)$. Note a presença de fragmento wsp apenas na raia 6. As raias 9 e 10 são os controles positivo e negativo, respectivamente.

Desta forma, o tratamento pela temperatura para a eliminação de Wolbachia dos hospedeiros demonstrou ser mais eficiente. Tal método foi, então, utilizado para a obtenção de moscas isentas de Wolbachia para os testes de incompatibilidade reprodutiva entre $A$. obliqua e $A$. sp.1, descritos a seguir.

\section{IV.4. Análise da incompatibilidade reprodutiva entre $A$. obliqua}

\section{e A. sp.1}

O estudo da incompatibilidade reprodutiva entre $A$. obliqua e $A$. sp.1 envolveu a análise de progênies de cruzamentos intra e interespecíficos com indivíduos, de ambas as espécies, que eram infectados pela Wolbachia (indicados pelo sinal +) e indivíduos curados pelo tratamento térmico das pupas (indicados pelo sinal - ). Foram analisadas a taxa de eclosão de larvas, a emergência e proporção sexual entre os adultos na geração $F 1$ desses 
cruzamentos. Os dados obtidos nessas análises estão mostrados na Tabela IV e representados graficamente na Figura 6.

Pela análise da Tabela IV, pode-se notar que as taxas de emergência dos diferentes cruzamentos foram variáveis, mas em níveis similares aos dos cruzamentos controle (espécies parentais), exceto no cruzamento entre fêmeas sp1- com machos obl+, onde a emergência foi mais baixa (25\%). Análises da eclosão das larvas e da proporção sexual entre os adultos, serão apresentadas a seguir.

\section{Cruzamentos intra-específicos com indivíduos infectados e/ou curados}

Utilizando-se indivíduos infectados, o cruzamento entre machos e fêmeas de sp1+ e o cruzamento similar de obl+, mostram que as taxas de eclosão foram elevadas (Tabela IV, Figura 6A). Nesses cruzamentos, a proporção sexual observada entre os adultos não se desviou significativamente do 1:1 esperado (Tabela IV, Figura 6B).

Quando foram utilizados indivíduos curados, observou-se nos cruzamentos entre machos e fêmeas de sp1- e entre machos e fêmeas de obl-, uma queda significativa nas taxas de eclosão quando comparadas às taxas dos cruzamento entre indivíduos infectados (Tabela IV, Figura 6A), como mostram os teste estatísticos da Tabela $V$. Além disso, nota-se que o decréscimo na taxa de eclosão foi maior em obliqua que em $A$. sp.1. Quanto às proporções sexuais entre os adultos, repetiu-se o observado com os cruzamentos entre indivíduos infectados, ou seja, a proporção não se alterou significativamente do 1:1 esperado (Tabela IV, Figura 6B).

Em outra série de experimentos, foram feitos cruzamentos intraespecíficos entre indivíduos infectados e curados, estando os dados na Tabela IV e Figura 6C. Nesses cruzamentos, quando a fêmea parental era curada mas o macho era infectado (fêmea sp1- x macho sp1+ e fêmea obl- x macho obl+), as taxas de eclosão foram significativamente menores que a dos cruzamentos recíprocos (fêmea sp1+ $x$ macho sp1- e fêmea obl+ $x$ macho obl-), como mostram a Figura $6 \mathrm{C}$ e os testes estatísticos da Tabela $\mathrm{V}$. Nesses cruzamentos, as proporções sexuais não se desviaram significativamente de 1:1, exceto em 


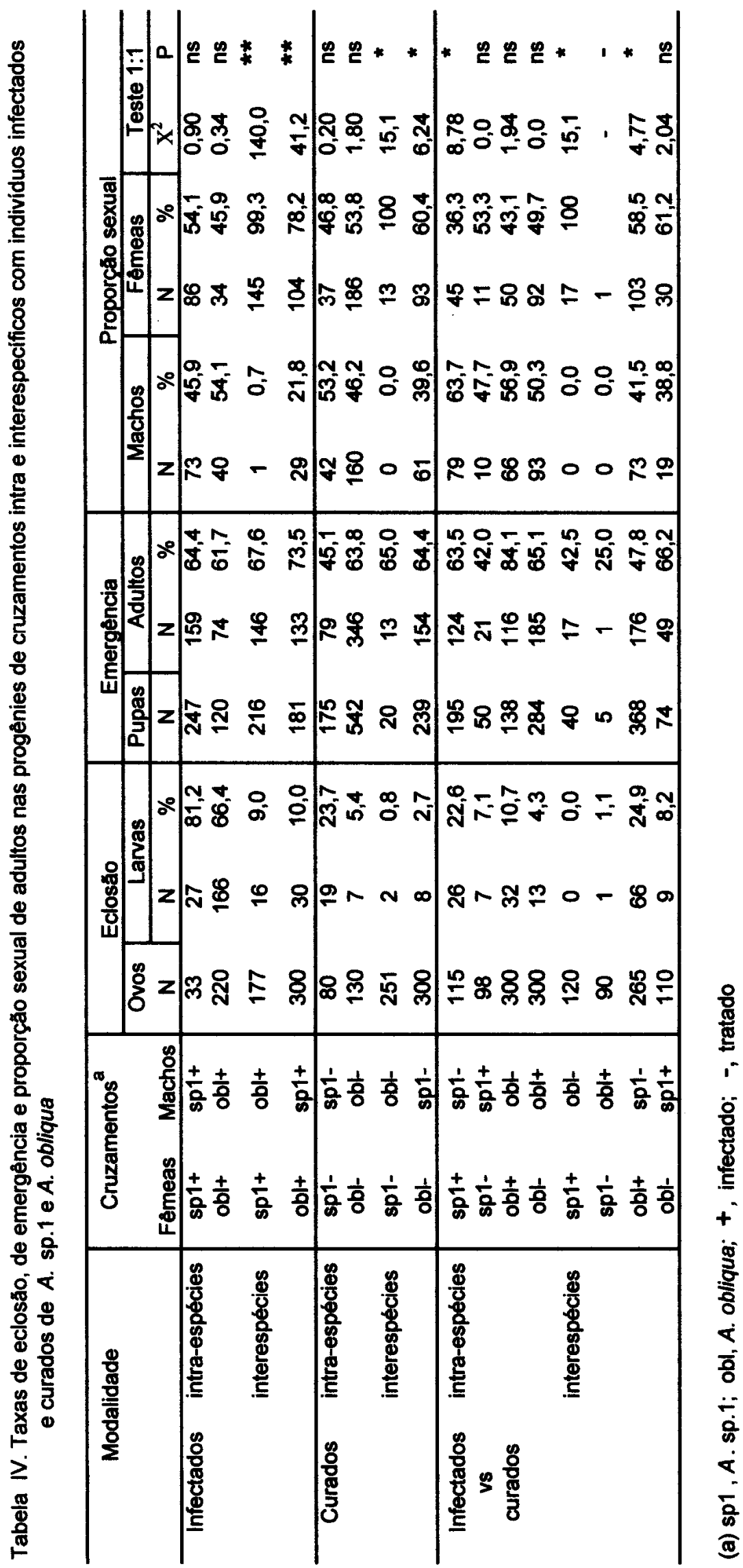




\section{ECLOSÄO}
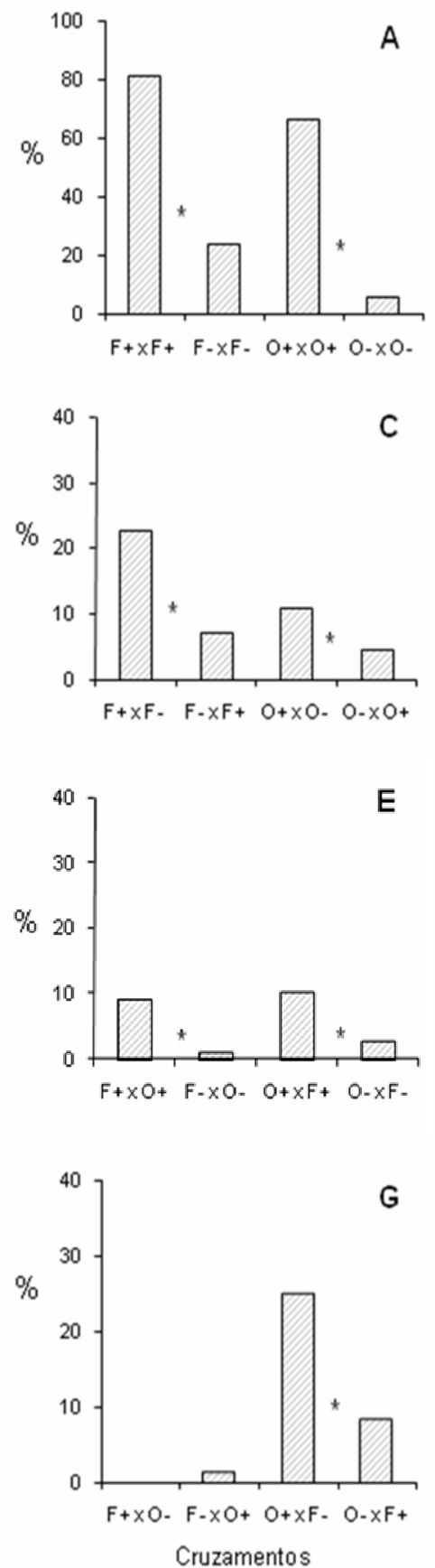

PROPORÇÄO

fêmeas $\square$ machos
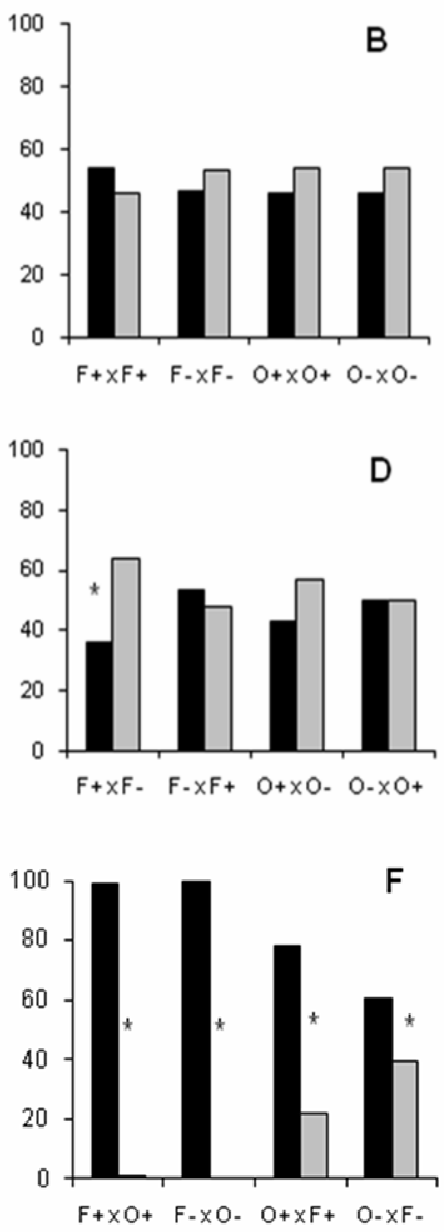

$\mathrm{H}$

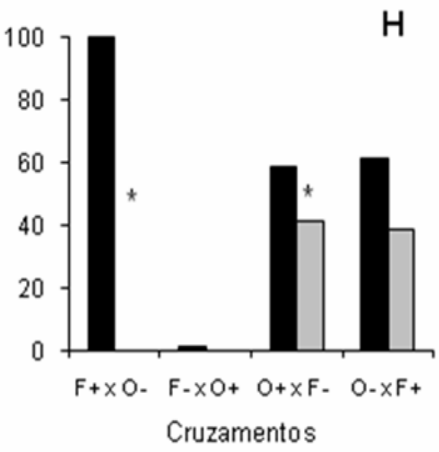

Figura 6. Taxas de eclosão de larvas e proporção sexual entre os adultos em progênies de cruzamentos de $A$. sp.1 e $A$. obliqua. Na coluna da esquerda estão os dados da eclosão e à direita, os da proporção sexual. $(A, B)$ cruzamentos intra-específicos com indivíduos infectados $(+)$ ou curados (-); (C,D) cruzamentos intra-específicos entre infectados e curados; (E,F) cruzamentos interespecíficos com indivíduos infectados ou curados; $(\mathrm{G}, \mathrm{H})$ cruzamentos interespecíficos entre infectados e curados. $\mathrm{Na}$ indicação dos cruzamentos (abcissas), o primeiro símbolo representa as fêmeas envolvidas e o segundo, os machos, p.ex., $\mathrm{F}+\mathrm{x}$ O-, indica o cruzamento entre fêmeas sp1 ( $F$, fraterculus) infectada com machos de obliqua curada. O símbolo * indica as diferenças significativas entre cruzamentos (dados da Tabela V). 
um deles, (fêmea sp1+ $x$ macho sp1-), onde os machos foram mais numerosos que as fêmeas (Tabela IV, Figura 6D).

\section{Cruzamentos interespecíficos com indivíduos infectados e curados}

Como demonstram a Tabela IV e a Figura 6E, em cruzamentos interespecíficos entre fêmeas sp1+ com machos obl+ e no cruzamento recíproco, as taxas de eclosão foram muito mais baixas que nos cruzamentos intraespecíficos das linhagens parentais. Essas taxas foram ainda menores nos cruzamentos entre fêmeas sp1- com machos obl- e no cruzamento recíproco. Em todos esses cruzamentos interespecíficos, foram observados desvios significativos na proporção sexual: quando as fêmeas foram de sp1+ ou sp.1-, as progênies eram constituídas quase que exclusivamente de fêmeas; entretanto, quando as fêmeas eram de obl+ ou obl-, ocorreram desvios significativos do 1:1, mas além de fêmeas, machos também foram produzidos nessas progênies (Tabela IV e Figura 6F).

$\mathrm{Na}$ série seguinte, foram feitos cruzamentos interespecíficos entre indivíduos infectados e curados. Como mostram a Figura $6 \mathrm{G}$ e os testes da Tabela $V$, quando as fêmeas parentais eram de sp1 (infectada ou não) e os machos de obliqua, a eclosão foi tão baixa nessas amostras de ovos que análises não puderam ser feitas. No entanto, no cruzamento de fêmea sp1+ com macho obl-, adultos foram obtidos e consistiam exclusivamente de fêmeas. Já no cruzamento recíproco (fêmea sp1- x macho obl+), apenas uma fêmea foi obtida (Tabela IV e Figura $6 \mathrm{H}$ ). Ao contrário, quando as fêmeas foram de obliqua e os machos de sp1, as progênies foram de tamanho similar às de outros cruzamentos envolvendo fêmeas de $A$. obliqua. Nesses cruzamentos, quando o macho parental era infectado (obl- x sp1+) a taxa de eclosão foi significativamente mais baixa (Tabela $V$ e Figura 6G) que no cruzamento recíproco (obl+ x sp1-). Na progênie adulta de ambos os cruzamentos, houve maior número de fêmeas que de machos, mas o desvio estatisticamente significativo da proporção esperada (1:1) somente foi observado para o cruzamento entre fêmea obl+ $x$ macho sp1- (Tabela IV, Figura 6). 
Tabela V. Comparações entre as taxas de eclosão ${ }^{a}$ dos diferentes cruzamentos envolvendo indivíduos infectados(+) e curados (-) de A. obliqua (O) e A. sp.1 (F)

\begin{tabular}{ccc}
\hline Comparações & $\chi^{2}$ & $\mathrm{P}$ \\
\hline F+ x F+ vs F-x F- & 10.98 & $0.01^{*}$ \\
O+ x O+ vs O- x O- & 63.85 & $<0.01^{* *}$ \\
& & \\
F+ x O+ vs O+ x F+ & 0.10 & $0.87 \mathrm{~ns}$ \\
F- x O- vs O- x F- & 0.16 & $0.197 \mathrm{~ns}$ \\
& & \\
F+ x F- vs F- x F+ & 6.20 & $0.013^{*}$ \\
O+ x O- vs O- x O+ & 6.65 & $0.01^{*}$ \\
F+ x O+ vs F- x O- & 6.79 & $<0.01^{* *}$ \\
O+ x F+ vs O- x F- & 10.86 & $<0.01^{* *}$ \\
O+x F- vs O- x F+ & 8.78 & $<0.01^{* *}$ \\
\hline
\end{tabular}

(a) dados na Tabela IV

$\left(\chi^{2}\right)$ Tabela de contingência $2 \times 2$ com correção de Yates 


\section{Discussão}

Nas últimas décadas enorme ênfase tem sido dada ao estudo da bactéria Wolbachia em razão dos efeitos que ela causa no sitema reprodutivo de seus hospedeiros (Werren, 1997, 1998).

Nas moscas-das-frutas da família Tephritidae, a presença da Wolbachia foi descrita em numerosas espécies (Werren et al. 1995; Selivon et al., 2002; Croscato, 2006; Mascarenhas, 2007), mas não existia, até o momento, nenhum estudo abordando os possíveis efeitos dessa bactéria nos seus hospedeiros.

As análises por PCR e seqüenciamento, demonstrando que as linhagens de laboratório das duas espécies de Anastrepha, A. obliqua e A. sp.1, estavam infectadas pela Wolbachia, ampliam os dados sobre a infecção nessas espécies que foram obtidos pela análise de amostras de populações naturais (Croscato, 2006; Mascarenhas, 2007). Embora o seqüenciamento do gene wsp de $A$. sp1 e de $A$. obliqua tenha mostrado que essas seqüências têm alta similaridade, inclusive com a seqüência wAu de Drosophila simulans (Charlat et al., 2004), é necessário lembrar que as linhagens presentes nas duas espécies podem diferir em outras características genéticas. Por essa razão, atualmente a identificação precisa das linhagens dessa bactéria tem sido feita pelo seqüenciamento conjunto de outros genes (Baldo \& Werren, 2007). Este fato, entretanto, não interfere com as propostas do presente trabalho que previa a comparação e cruzamentos de linhagens infectadas com linhagens isentas (curadas) de Wolbachia, para testar os efeitos nos seus hospedeiros, em outras palavras, procurar evidências de IC, mediada por Wolbachia, em espécies de Anastrepha.

A análise citológica dos embriões mostrou que nas duas espécies de Anastrepha aqui estudadas, a maior concentração da Wolbachia no pólo posterior dos embriões é similar ao descrito em $A$. sp.2 aff. fraterculus (Selivon et al., 2002) e também, em embriões de outros insetos, p.ex., Drosophila (Hadfield \& Axton, 1999), nas vespas Trichogramma (Stouthamer \& Werren, 1993) e Nasonia ( Breeuwer \& Werren, 1993) e no sciarídeo Sciara ocellaris (Gutzeit et al., 1985; Ribeiro \& Perondini, 1991). Segundo alguns autores (Bourtzis et al., 2003), a localização nessa região do embrião favoreceria a 
transmissão vertical dessa bactéria, pois elas são incorporadas nas células polares tão logo estas se formam, como mostrado, p.ex., em Anastrepha sp.2 aff. fraterculus (Selivon et al., 2002).

Os dados também indicam não haver diferenças marcantes na densidade de bactérias entre os embriões de $A$. obliqua e de $A$. sp1. Alguns autores presumem que existem mecanismos que de alguma forma autoregulam a densidade das bactérias desde que elas são transmitidas verticalmente e seriam selecionadas por reduzir efeitos que confeririam valor adaptativo negativo às fêmeas nas quais elas ocorrem (Turelli, 1994; Werren \& O’Neill, 1997). Assim, as bactérias regulariam a taxa de replicação para minimizar efeitos negativos nos hospedeiros, mas ainda manteriam densidade populacional suficiente para protegê-las contra a IC. Em Drosophila simulans, uma linhagem que aparentemente perdeu essa auto-regularão, apresentou degeneração neural e a morte precoce dos adultos. Se a auto-regularão da densidade de bactérias é correta, então o ponto de equilíbrio dependeria do genótipo do hospedeiro (Bourtzis et al., 2003). A aparente diferença na densidade de bactérias em $A$. sp.1 e $A$. obliqua pode estar relacionada a um efeito dessa natureza. Esse é um aspecto a ser explorado futuramente, incluindo a análise mais detalhada da densidade populacional em embriões híbridos.

Embora não seja possível afirmar, pelo método de coloração com o fluorocromo DAPI, que as bactérias visíveis nas preparações citológicas sejam Wolbachia, há fortes indícios de que elas sejam predominantes nos embriões, pois sua presença foi detectada por PCR em outras amostras de embriões de A. sp.1 (Croscato, 2006) e também, em embriões de A. sp.2 (Selivon et al., 2002). É possível, entretanto, que outras bactérias não identificadas estejam presentes nos ovos de Anastrepha, como ocorre em numerosas espécies de insetos. Postula-se que outros tipos de bactérias associadas a Wolbachia possam também causar distorções em aspectos reprodutivos dos hospedeiros. Por exemplo, bactérias CFB (Cytophaga-Flavobacterium-Bacteroids), CLO (Cytophaga-like-organisms) estão associadas com fenômenos de feminização, determinação do sexo e partenogênese. Entretanto, as informações sobre esses grupos de bactérias são mais escassos do que para Wolbachia (rev. Weeks \& Breeuwer, 2003). 
Para a realização dos experimentos era necessária o estabelecimento de colônias das duas espécies de moscas-das-frutas isentas de Wolbachia. Deste modo, e como não foram encontradas populações naturais nãoinfectadas (Coscrato, 2006; Mascarenhas, 2007), foi necessário eliminar-se as bactérias das colônias infectadas do laboratório. Para tanto, dois métodos descritos na literatura foram testados: tratamento com o antibiótico tetraciclina (Yen \& Barr, 1974; Breeuwer \& Werren, 1993; Werren, 1997) ou pelo tratamento térmico dos indivíduos infectados (Werren, 1997; Bourtzis \& O’Neill, 1998). Os resultados demonstram que as bactérias foram mais eficientemente eliminadas pelo tratamento térmico das pupas do que pelo tratamento com tetraciclina. Não se sabe a que se deve esta diferença, pois em outras espécies de insetos ambos os tratamentos são eficazes para a eliminação da Wolbachia.

A obtenção de adultos de ambos os sexos, livres de Wolbachia (curadas) através do tratamento térmico das pupas foi viável, mas com aumento na mortalidade das pupas. Essa queda nas taxas de emergência, observadas em relação à populações infectadas, não tem grandes implicações, a não ser para o estabelecimento das colônias com indivíduos curados. Entretanto, a emergência foi suficiente (31,2\% em $A$. obliqua e 52,9\% em $A$. sp1), para o estabelecimento de colônias isentas de Wolbachia e foi, a partir dessas populações iniciadas pelos indivíduos curados, que os os experimentos para testar os efeitos da Wolbachia nos seus hospedeiros foram realizados.

A literatura mostra que o tratamento com tetraciclina é eficiente em vários casos, por exemplo, no estudo de IC em Drosophila simulans, o antibiótico foi adicionado ao meio de cultura numa concentração final de 0,05\%, tendo sido obtida com sucesso a linhagem curada. No presente trabalho, o tratamento mesmo com concentração mais alta (1\%) não apresentou bom rendimento. A supressão de IC em linhagens de hospedeiros tratados por calor já era conhecida (Wright \& Wang, 1980) ainda que as razões para esse efeito não fossem conhecidas. Hoffmann et al. (1986) aplicando temperatura de 30 $32^{\circ} \mathrm{C}$ observaram a supressão da IC em D. simulans e postularam que microrganismos deveriam estar envolvidos. O presente trabalho corroborou que o tratamento em alta temperatura elimina as Wolbachia associadas aos indivíduos tratados, ainda que causem maior mortalidade, seja pela própria eliminação do simbionte, ou por outro tipo de perturbação exercida durante a 
metamorfose. Uma redução na taxa de emergência de adultos de A. obliqua a partir de pupas submetidas ao calor, também foi observada por Pires (2005).

A eliminação das Wolbachia causa, de modo geral, uma queda na taxa de eclosão nas progênies dos diferentes cruzamentos (Figura A, C, E, G). Em outros insetos demonstrou-se que a eliminação das Wolbachia causa uma redução no desempenho reprodutivo das fêmeas sugerindo um efeito da infecção no valor adaptativo do hospedeiro (Dedeine et al., 2003).

Os resultados dos cruzamentos intra-específicos (Fig. 6C) nos quais verificou-se redução na taxa de eclosão quando os machos infectados foram cruzados com fêmeas curadas, mostraram claramente a existência de IC associada à Wolbachia. Esses dados estão de acordo com o modelo de modificação/ recuperação - mod/rec - (Werren, 1997), ou seja, os gametas de machos infectados que teriam sofrido a modificação não são compatíveis com ovos de fêmeas que não possua o sistema de recuperação. Os resultados da Figura 6A também são compatíveis, onde machos e fêmeas infectados apresentariam os fatores $\mathrm{mod} / \mathrm{rec}$ e os cruzamentos entre indivíduos curados não teriam incompatibilidade por não terem nenhum fator de mod/rec.

Nos cruzamentos interespecíficos entre indivíduos infectados e indivíduos curados, as taxas de eclosão foram baixas nos indivíduos infectados e ainda menores nos cruzamentos de indivíduos curados, possivelmente pelos motivos já comentados. Uma vez que nesses cruzamentos não se esperaria IC, a baixa eclosão possivelmente é devida às diferenças genéticas entre os hospedeiros.

Em cruzamentos interespecíficos entre indivíduos infectados com curados (Figura 6G), nota-se taxas de eclosão extremamente baixas quando as fêmeas são de sp1, mas taxas maiores, embora assimétricas nos cruzamentos recíprocos, quando as fêmeas eram de obliqua, o que sugere, segundo o modelo $\mathrm{mod} / \mathrm{rec}$, a existência de IC entre as espécies.

É relevante notar o resultado do cruzamento de fêmeas obl+ $x$ machos sp1+, mostrado na Figura 6E, quando comparado ao cruzamento de fêmeas obl+ x machos sp1- (Fig. 6G). Pelo modelo do mod/rec, os resultados desses dois cruzamentos deveriam ser similares. Entretanto, a taxa de eclosão do primeiro (obl+ x sp1+) é, praticamente, metade daquela observada no outro. Estes resultados poderiam ser explicados se as linhagens de Wolbachia 
existentes nas colônias de obliqua e de sp.1 não fossem tão similares, ou então, se apresentarem diferenças em outras regiões do genoma, ou ainda, se assumirmos a presença de outras bactérias causadoras de IC.

A existência de IC, congruente com o modelo de mod/rec, foi descrita em vários insetos (revisões Werren, 1997; Dobson, 2003; Bourtzis et al., 2003) e também, em outros gêneros de moscas-das-frutas. Em populações de Rhagoletis cerasi de diferentes regiões da Europa, foram encontradas duas diferentes linhagens de Wolbachia que explicariam os casos de IC descritos anteriormente, mas sem que a etiologia fosse elucidada (Riegler \& Stauffer, 2002). IC foi também descrita em Ceratitis capitata, que foi infectada artificialmente em laboratório com Wolbachia de Rhagoletis cerasi, visando o desenvolvimento de método de controle populacional alternativo ao TIE (Zabalou et al., 2004).

Já eram conhecidos resultados da literatura (Santos et al., 2001) mostrando que nos cruzamentos recíprocos entre obliqua e sp.1, ocorrem desvios na proporção sexual entre os adultos. Esses fatos foram corroborados no presente trabalho quando as linhagens infectadas foram cruzadas entre si, como veremos a seguir.

A proporção sexual manteve-se em 1:1 nas progênies adultas dos cruzamentos intra-específicos, independentemente dos parentais estarem ou não infectados pela Wolbachia (Figura 6B, 6D). A exceção foi o cruzamento de fêmeas sp1+ x sp1- (Figura 6D), no qual houve uma redução no número de fêmeas. Este é um resultado de difícil interpretação uma vez que não seria esperado, considerando-se a ausência de Wolbachia nos machos parentais. É muito possível que tenha ocorrido um problema amostral ou experimental nesses cruzamentos.

Os resultados obtidos na proporção sexual das progênies dos cruzamentos interespecíficos (Figura 6F) estão de acordo com os resultados obtidos anteriormente por Santos et al. (2001). Quando a fêmea parental é sp.1 há praticamente $100 \%$ de fêmeas na progênie, mas quando a fêmea é obliqua, recupera-se também um certo número de machos. Esses autores interpretaram os resultados como casos da regra de Haldane e/ou efeitos citoplasmáticos. Os dados obtidos no presente trabalho mostram que os resultados desse tipo de cruzamento são pouco alterados com a presença ou ausência de Wolbachia 
nos indivíduos parentais (Figura 6F). Entretanto, o cruzamento de fêmeas obl+ $x$ machos sp1- (Figura $6 \mathrm{H}$ ) quando comparado ao cruzamento de fêmeas de obl+ $\mathrm{x}$ machos sp1+ (Figura 6F), mostra que quando os machos parentais estão curados, há uma recuperação maior de machos na progênie. Isso sugere que deve existir uma interação entre a Wolbachia e a incompatibilidade existente entre os genomas das espécies hospedeiras. Interrelações dessa natureza já foram observadas em Drosophila e Nasonia (Bourtzis et al., 2003). Pela análise dos resultados das Figura $6 \mathrm{~B}, \mathrm{D}, \mathrm{F}, \mathrm{H}$, é possível verificar se há ou não morte diferencial entre os sexos ao comparar com as taxas de eclosão das Figura 6 A, C, E, G.

O fato da Wolbachia, pelo mecanismo de IC agir como um fator de especiação tem gerado muita controvérsia. $O$ conceito básico é que IC, por prevenir ou severamente reduzir o fluxo gênico entre populações favoreceria a divergência entre espécies. Existem dois modos através dos quais a Wolbachia poderia estar diretamente envolvida em processos de especiação. Primeiramente, a IC bidirecional estaria entre as causas primárias de isolamento reprodutivo pois promoveria um isolamento "instantâneo", propiciando, posteriormente, o acúmulo de divergência genética nos hospedeiros. Em segundo lugar, a IC unidirecional contribuiria para o isolamento entre populações que estivessem em processo de divergência. Assim, a IC unidirecional não seria uma das causas primárias do isolamento reprodutivo, mas seria um fator essencial na manutenção do isolamento entre espécies incipientes. Na aquisição de diferentes linhagens de Wolbachia seria particularmente importante o fato de ocorrer transferência horizontal dessas bactérias, vindas de um outro organismo associado (Werren, 1998; Telschow \& Werren, 2005). Existem evidências que tal processo ocorra entre espécies Anastrepha, mediado por himenópteros parasitóides associados (Mascarenhas, 2007). As alterações em aspectos reprodutivos das espécies de Anastrepha aqui estudadas, associadas com Wolbachia, não permitem descartar a possibilidade de que essa bactéria possa, eventualmente, estar envolvida nos processos de divergência de espécies nesse grupo de insetos.

Em conclusão, este trabalho apresenta a primeira demonstração de IC em Anastrepha. As implicações desse fenômeno para o entendimento da divergência entre espécies desse grupo, bem como possíveis aplicações em 
aspectos práticos no manejo desses insetos-praga, deverão ser abordados no futuro. 


\section{CONCLUSÕES}

- As colônias de laboratório de $A$. sp1 aff. fraterculus e $A$. obliqua estão infectadas pela bactéria endossimbionte Wolbachia.

- Nos embriões das duas espécies, as bactérias distribuem-se em gradiente decrescente do pólo posterior para o pólo anterior.

- O tratamento térmico a $30^{\circ} \mathrm{C}$ é mais eficiente que o tratamento com tetraciclina para eliminar as bactérias de seus hospedeiros.

- O tratamento eleva a taxa de mortalidade no estágio de pupas porém afeta igualmente machos e fêmeas.

- Nas duas espécies, a eliminação das Wolbachia causa um decréscimo nas taxas de eclosão em relação à eclosão das linhagens infectadas, mas nenhuma alteração na proporção sexual entre os adultos.

- A Wolbachia está associada a ocorrência de incompatibilidade citoplasmática (IC) tanto em A. obliqua quanto em A. sp.1.

- Existe IC associada a Wolbachia nas progênies obtidas de cruzamentos entre fêmeas de obliqua com machos sp.1.

- Há uma redução significativa na taxa de eclosão das larvas da progênie híbrida obtida em cruzamentos entre A. obliqua e A. sp.1. Tal redução é ainda mais drástica quando a Wolbachia é eliminada.

- A eliminação das Wolbachia não interferem na proporção sexual das progênies das duas espécies de Anastrepha,

- A proporção sexual da progênie obtida a partir dos cruzamentos entre $A$. obliqua e A. sp.1 infectados, apresentou desvios significativos de acordo com a regra de Haldane, corroborando dados da literatura.

- A eliminação da Wolbachia altera a proporção sexual em cruzamentos interespecíficos de indivíduos infectados com curados. 


\section{RESUMO}

Wolbachia é um gênero de bactérias endossimbiontes que são verticalmente transmitidas pelas fêmeas aos seus descendentes, embora transmissão entre táxons distintos também ocorra com certa freqüência. Entre os efeitos que essa bactéria causa nos sistemas de reprodutivos de seus hospedeiros destaca-se a incompatibilidade citoplasmática (IC). Wolbachia foi descrita em numerosas espécies de artrópodos, especialmente os insetos. Dentre os insetos, essa bactéria foi descrita em diversos gêneros das moscasdas-frutas da familia Tephritidae, tendo sido demonstrada a IC em Rhagoletis cerasi e Ceratitis capitata. Recentemente, essas bactérias foram identificadas nas moscas-das-frutas do gênero Anastrepha. No presente trabalho, procurouse demonstrar se a Wolbachia estaria relacionada a IC entre Anastrepha sp.1 aff. fraterculus e Anastrepha obliqua. A amplificação e o seqüenciamento do gene wsp revelou que as populações das duas espécies, mantidas no laboratório, estavam infectadas por Wolbachia. A presença da bactéria foi, também, demonstrada citologicamente em embriões corados pelo DAPI, tendose, além disso, observado que elas se distribuem nos embriões em gradiente decrescente do pólo posterior para o anterior. Para testar a hipótese de que a bactéria é a causa da IC, foram estabelecidas populações das duas espécies onde a Wolbachia (e possivelmente outras bactérias não identificadas) foram eliminadas por tratamento térmico $\left(30^{\circ} \mathrm{C}\right)$ aplicado às pupas. As taxas de eclosão de larvas nas progênies de cruzamentos entre indivíduos curados, foram menores que a eclosão nos cruzamentos entre indivíduos infectados, mas o tratamento não alterou a proporção sexual dos adultos. Cruzamentos intra-específicos entre indivíduos infectados e curados, produziu assimetria nas progênies dos cruzamentos recíprocos, ou seja, quando os fêmeas eram curadas e os machos infectados a taxa de eclosão foi significativamente menor que nos cruzamentos recíprocos demonstrando, assim, a existência de IC unidirecional nos cruzamentos dessas duas espécies de Anastrepha. Nesses cruzamentos, a proporção sexual das progênies adultas não divergiu significativamente do 1:1 esperado. Nas progênies híbridas de cruzamentos interespecíficos entre indivíduos infectados, observou-se um decréscimo 
significativo nas taxas de eclosão e alteração na proporção sexual entre os adultos, de acordo com a regra de Haldane. Quando as fêmeas eram de $A$. sp.1, as progênies eram constituídas apenas por fêmeas e quando eram de $A$. obliqua, machos também foram produzidos, mas em frequências menores que o esperado. Resultados similares foram obtidos quando indivíduos curados foram cruzados entre si. Cruzamentos interespecíficos de indivíduos infectados cruzados com indivíduos curados, produziram progênies com taxas de eclosão muito reduzidas e menores quando as fêmeas eram de $A$. sp.1 (infectadas ou curadas), do que nos cruzamentos onde as fêmeas eram de $A$. obliqua (infectadas ou não). Nestes últimos, quando a fêmea era infectada e os machos curados, a taxa de eclosão foi maior que no cruzamento recíproco, demonstrando a presença de IC entre as duas espécies. A proporção sexual também foi alterada nesses cruzamentos, segundo a regra de Haldane. Os resultados do presente trabalho demonstram, pela primeira vez, que a incompatibilidade citoplasmática mediada pela Wolbachia, ocorre nas duas espécies de Anastrepha e sugerem que deve existir uma interação entre a bactéria e os genomas das espécies hospedeiras. 


\section{ABSTRACT}

The endosymbiont bacteria Wolbachia are vertically transmitted by the females to its progenies, although horizontal transmission between distinct taxa is also known. One of the most relevant effects caused by these bacteria in the reproductive behavior of its hosts is the cytoplasmic incompatibility $(\mathrm{Cl})$. Wolbachia was described in several groups of arthropods, in the insects including several genera of the tefritid fruit flies. Wolbachia-induced $\mathrm{Cl}$ was reported in Rhagoletis cerasi and Ceratitis capitata. Recently, occurrence of these bacteria was described in several species of genus Anastrepha. Search for possible Wolbachia-induced $\mathrm{Cl}$ in crosses of Anastrepha obliqua and A. sp.1 aff. fraterculus was the aim of the present study. Amplification and sequencing of the gene wsp of Wolbachia revealed that laboratory colonies of both species were infected with this bacteria. Cytological analysis of embryos stained with DAPI showed a multitude of bacteria distributed in decreasing gradients from the posterior to the anterior pole of the embryos. The hypothesis that there is $\mathrm{Cl}$ between the two host species was tested using infected and cured individuals. The bacteria were removed by treating the pupae at the temperature of $30^{\circ} \mathrm{C}$. Rate of egg hatch in progenies recovered from crosses of cured flies were lower than egg hatch in crosses of the infected strains, but no sex-ratio deviation from the expected 1:1 was observed. Intra-specific crosses between infected and cured individuals resulted in asymmetries in the progenies of reciprocal crosses. The egg hatch in crosses of cured obliqua females to infected sp. 1 males was lower than in the reciprocal crosses, clearly indicating the presence of Wolbachia-induced $\mathrm{Cl}$ in Anastrepha. In these crosses, sex-ratio among the adults does not deviate from the 1:1 ratio. In the hybrid progenies of interspecific crosses, it was observed a decrease in the egg hatch rate, and deviation from $1: 1$ in the adult sex-ratio according to the Haldane's rule. From crosses of sp.1 females to obliqua males, only females were recovered while in crosses of obliqua females to sp. 1 males, males were also produced but in lower frequencies than expected. Similar results were obtained when cured individuals were crossed. Very low egg hatch rates were observed in interspecific crosses of infected to cured individuals, when sp.1 females (infected or 
cured) were used. In crosses of obliqua females (infected or cured), higher egg hatch rate was observed. Egg hatch was larger in crosses of infected female to cured males than in the reciprocal crosses, indicating a Wolbachia-induced IC between the two species of Anastrepha. The sex-ratios were also according to the Haldane's rule. This is the first report of Wolbachia-induced $\mathrm{Cl}$ in Anastrepha. The existence of a possible interaction between the bacteria and the genomes of the host species is also suggested. 


\section{REFERÊNCIAS BIBLIOGRÁFICAS}

Aluja,M. 1994. Bionomics and Management of Anastrepha. Annual Review. of Entomology. 39: 155-178.

Baldo, L.; Lo, N. \& Werren, J.H. 2005. Mosaic Nature of the Wolbachia Surface Protein. Journal of Bacteriology. 185 (15): 5406-5418.

Baldo, L. \& Werren, J.H. 2007. Revisiting Wolbachia Supergroup Typing Based on wsp: Spurious Lineages and Discordance with MLST. Current Microbiology 55: 81-87.

Barr, N.B.; Cui, L.; McPheron, B.A. 2005. Molecular Systematics of Nuclear Gene period in genus Anastrepha (Tephritidae). Annals of the Entomological Society of America: 98(2): 173-180.

Beard, C.B.; O'Neill, S.L.; Tesh, R.B.; Richard, F.F. \& Aksoy, S. 1993. Modification of arthropod vector competence via symbiotic bacteria. Parasitology Today, 9: 179-183.

Bourtzis, K.; Braig, H. R. \& Karr, T. L. 2003. Cytoplasmic Incompatibility. p. 217246. Em: "Insect Symbiosis". Bourtzis, K. \& Miller, T. A. (ed.). CRC Press. Boca Raton, Florida.

Bourtzis, K. \& O'Neill, S.L., 1998. Wolbachia infections and arthropod reproduction. Bioscience 48, 287-293.

Breeuwer, J.A.J. 1997. Wolbachia and cytoplasmic incompatibility in the spider mites Tetranychus urticae and T. Turkestani. Heredity 79: 41-47.

Breeuwer, J.A.J. \& Werren, J.H. 1993. Cytoplasmic Incompatibility and Bacterial Density in Nasonia vitripennis. Genetics 135: 565-574.

Charlat, S.; Ballard, J.W.O. \& Merçot, H. 2004. What maintains noncytoplasmic incompatibility inducing Wolbachia in their hosts: a case study from a natural Drosophila yakuba population. Journal of Evolutionary Biology 17: 322-330.

Clark, M.E.; Bailey-Jourdain, C.; Ferree, P.M.; England, S. J.; Sullivan, W.; Windsor, D. M. \& Werren, J. H. 2008. Wolbachia modification of sperm does not always require residence within developing sperm. Heredity 101: 420-428.

Coscrato, V.E. 2006. Detecção e filogenia da bactéria Wolbachia em moscasdas-frutas Ceratitis capitata e em espécies de Anastrepha (Diptera: 
Tephritidae). Tese de doutorado. Instituto de Biociências de Botucatu, Universidade Estadual Paulista, SP.

Dedeine, F.; Bandi, C.; Boulétreau, M \& Kramer, L.H.. 2003. Insights into Wolbachia Obligatory Symbiosis. p. 267-282. Em: "Insect Symbiosis". Bourtzis, K. \& Miller, T. A. (ed.). CRC Press. Boca Raton, Florida.

Dedeine, F.; Vavre, F.; Fleury, F.; Loppin, B.; Hochberg, M.E. \& Boulétreau, M. 2001. Removing symbiotic Wolbachia bacteria specifically inhibits oogenesis in a parasitic wasp. Proceedings of National Academy of Science 98: 62476252.

Dobson, S. L. 2003. Wolbachia pipientis: Impotent by Association. p. 199-216. Em: "Insect Symbiosis". Bourtzis, K. \& Miller, T. A. (ed.). CRC Press. Boca Raton, Florida.

Dobzhansky, T. 1937. Genetics and the origin of species. Columbia University Press, New York.

Frydman, H.M., Li, J.M., Robson, D.N. \& Wieschaus, E. 2006. Somatic stem cell niche tropism in Wolbachia. Nature 441: 509-512.

Gutzeit, H.O.; Zissler, D. \& Perondini, A.L.P. 1985. Intracellular translocation of symbiotic bacteroids during late oogenesis and early embryogenesis of Bradysia tritici (syn. Sciara ocellaris) (Diptera; Sciaridae). Differentiation 29: 223-229.

Hadfield, S.J. \& Axton, J.M. 1999. Germ cells colonized by endosymbiotic bacteria. Nature 402: 482.

Hariri, A.R., Werren, J.H. \& Wilkinson, G.S. 1998. Distribution and reproductive efects of Wolbachia in stalk-eyed flies (Diptera: Diopsidae). Heredity 81, 254-260.

Hilgenboecker, K.; Hammerstein, P.; Schlattmann, P.; Telschow, A. \& Werren, J.H. 2008. How many species are infected with Wolbachia? - a statistical analysis of current data. FEMS Microbiology Letters 281: 215-220.

Hoffmann, A.A.; Hercus, M. \& Dagher, H. 1998. Population Dynamics of the Wolbachia Infection Causing Cytoplasmic Incompatibility in Drosophila melanogaster. Genetics 148:221-231.

Hoffmann, A.A.; Turelli, M.; Simmons, G.M. 1986. Unidirectional Incompatibility between populations of Drosophila simulans. Evolution 40: 692-701. 
Hurst, G.D.D.; Jiggins, F.M.; Schulenburg, H.G.J.; Bertrand, D.; West, S.A.; Goriacheva, I.I.; Zakharov, I.A.; Werren, J.H.; Stouthamer, R. \& Majerus, M.E.N. 1999. Male-killing Wolbachia in two species of insect. Proceedings of Royal Society of London B 266: 735-740.

Jamnongluk, W., Kittayapong, P.; Baimai, V. \& O'Neill, S.L. 2002. Wolbachia infections of tephritid fruit flies: molecular evidence for five distinct strains in a single host species. Current Microbiology 45:255-260.

Jeyaprakash, A. \& Hoy, M.A. 2000. Long PCR improves Wolbachia DNA amplification: wsp sequences found in $76 \%$ of sixty-three arthropod species. Insect Molecular Biology 9: 393-405.

Jigging, F.M.; Bentley, M., E., N.; MAJERUS \& G. D. D. HURST, 2001 How many species are infected with Wolbachia? Cryptic sex ratio distorters revealed to be common by intensive sampling. Proceedings of Royal Society of London B 268: 1123-1126.

Jowett, T. 1986. Preparation of nucleic acids. Em: Drosophila: A Practical Approach. D.B. Roberts, D.B. (ed). Oxford: IRL Press Limited.

Keller, G.P.; Windsor, D.M.; Saucedo, J.M. \& Werren, J.H. 2004. Reproductive effects and geographical distribution of two Wolbachia strains infecting the neotropical beetle, Chelymorpha alternans Boh. (Chrysomelidae, Cassidinae). Molecular Ecology 13: 2405-2420.

Kittayapong, P.; Milne, J.R.; Tigvattananont, S. \& Baimai, V. 2000. Distribution of the reproduction-midifying bacteria, Wolbachia, in natural populations of tephritid fruit flies in Thailand. Science Asia 26: 93-103.

Koivisto, R.K.K. \& Braig, H.R. 2003. Microorganisms and parthenogenesis. Biological Journal of Linnean Society 79: 43-58.

Kondo, N.; Nikoh, N.; ljichi. N.; Shimada, M. \& Fukatsu, T. 2002. Genome fragment of Wolbachia endosymbiont transferred to $X$ chromosome of host insect. Proceedings of National Academy of Science 99: 14280-14285.

Kose, H. \& Karr, T.L. 1995. Organization of Wolbachia pipientis in the Drosophila fertilized egg and embryo revealed by an anti-Wolbachia monoclonal antibody. Mechanisms of Development 51: 275-288.

Koukou, K.; Pavlikaki, H.; Kilias, G.; Werren, J.H.; Bourtzis, K. \& Alahiotis, S.N. 2006. Influence of antibiotic treatment and Wolbachia curing on sexual 
isolation among Drosophila melanogaster cage populations. Evolution, 60: 87-96.

Lavagnolli, T.; Mascarenhas, R.; Rocha, L.; Perondini, A.L.P. \& Selivon, D. 2005. Detecção de Wolbachia em amostras de insetos da região Neotropical. CD-ROM do $51^{\circ}$. Congresso Nacional de Genética, Águas de Lindóia, SP, Brasil.

Lo, N.; Casiraghi, M.; Salati,E.; Bazzocchi,C. \& Bandi, C. 2002. How Many Wolbachia Supergroups Exist? Molecular Biology and Evolution 19(3):341346.

Lo, N.; Paraskevopoulos, C.; K. Bourtzis, K.; O'Neill, S.L.; Werren, J.H.; Bordenstein, S.R. \& Bandi, C. 2007. Taxonomic status of the intracellular bacterium Wolbachia pipientis. International Journal of Systematic and Evolutionary Microbiology 57: 654-657.

Malavasi, A.; Zucchi, R.A. \& Sugayama, R. L. 2000. Biogegrafia. p.93-98 Em: "Moscas-das-frutas de Importância Econômica no Brasil: Conhecimento Básico e Aplicado". Malavasi, A. \& Zucchi, R. A. (ed.). Holos, Ribeirão Preto. Mascarenhas, R.O. 2007. Endossimbionte Wolbachia em moscas-das-frutas do gênero Anastrepha (Tephritidae) e em vespas parasitóides (Braconidae) associadas. Dissertação de Mestrado. Depto de Biologia, Instituto de Biociências, Universidade de São Paulo, SP.

McGraw, E.A.; Merritt, D.J., Droller, J., N. \& O'Neill, S.L. 2002. Wolbachia density and virulence attenuation after transfer into a novel host. Proceedings of National Academy of Science 99(5): 2918-2923.

Mouton, L.; Henri, H.; Bouletreau, M. \& Vavre, F. 2003. Strain-specific regulation of intracellular Wolbachia density in multiply infected insects. Molecular Ecology 12: 3459-3465.

Murillo, T. \& Jirón, L. F. 1994. Egg morphology of Anastrepha obliqua and some comparative aspects with eggs of Anastrepha fraterculus (Diptera:Tephritidae). Florida Entomologist 77(3):342-348.

Nikoh, N.; Tanaka, K.; Shibata, F.; Kondo, N.; Hizume, M.; Shimada, M. \& Fukatsu, T. 2008. Wolbachia genome integrated in an insect chromosome: Evolution and fate of laterally transferred endosymbiont genes. Genome Research. 18: 272-280. 
Norrbom, A.L.; Zucchi, R.A.; Hernández-Ortiz, V. 1999. Phylogeny of the genera Anastrepha and Toxotrypana (Trypetinae: Toxotrypanini) based on morphology. P. 299-342. Em: Fruit flies (Tephritidae): phylogeny and evolution of behavior. Aluja, M.; Norrbom, A.L. (eds.) CRC Press, Boca Ratón, Flórida.

O’Neill, S. L.; Giordano,R.; Colbert, A. M. E. \& Karr,T. L.; Robertson, H. M. 1992. 16S rRNA phylogenetic analysis of the bacterial endosymbionts associated with cytoplasmatic incompatibility in insects. Proceedings of National Academy of Science USA 89:2699-2702.

Panaram, K. \& Marshall, J. L. 2007. F supergroup Wolbachia in bush crickets: what do patterns of sequence variation reveal about this supergroup and horizontal transfer between nematodes and arthropods? Genetica: 130:5360.

Pires, A. O. 2005. Variações no padrão simétrico de cerdas em diferentes condições de desenvolvimento em Anastrepha (Diptera: Tephritidae). Tese de Doutorado. Depto de Biologia, Instituto de Biociências, Universidade de São Paulo, SP.

Prezotto, L.F. 2008. Análise do ITS1 do DNA ribossômico em espécies do complexo Anastrepha fraterculus (Diptera: Tephritidae). Dissertação de Mestrado. Depto de Biologia, Instituto de Biociências, Universidade de São Paulo, SP.

Ribeiro, A.F. \& Perondini, A.L.P. 1991. Symbiont bacteroids in eggs and germ cells of Sciara ocellaris (Diptera;Sciaridae). Inverterbrate Reproduction and Development. 19: 127-133, 1991.

Riegler, M. \& Stauffer, C. 2002. Wolbachia infections and superinfections in cytoplasmically incompatible populations of the European cherry fruit fly Rhagoletis cerasi (Diptera, Tephritidae). Molecular Ecology 11: 2425-2434.

Rocha, L.S.; Mascarenhas, R.O.; Perondini, A.L.P. \& Selivon, D. 2005. Occurrence of Wolbachia in brazilian samples of Ceratitis capitata (Wiedemann) (Diptera: Tephritidae). Neotropical Entomology 34: 1013-1015.

Rocha, L.S.; Selivon, D. 2004. Studies on highly repetitive DNA in cryptic species of the Anastrepha fraterculus complex (Diptera: Tephritidae), p.415418. Em: Proc. $6^{\text {th }}$ International Fruit Flies Symposium, 6-10 May 2002, 
Stellenbosch, South Africa, Barbes, B. (ed.), Isteg Scientific Publication, Irene, África do Sul.

Rousset, F.; Raymond, M. \& Kjellberg, F. 1992. Wolbachia endosymbionts responsible for various alterations of sexuality in arthropods. Proceedings of Royal Society of London B 250: 91-98.

Salles, L.A.. 2000. Biologia e ciclo de vida de Anastrepha fraterculus (Wied.). p. 81-86. Em: "Moscas-das-frutas de Importância Econômica no Brasil: Conhecimento Básico e Aplicado". Malavasi, A. \& Zucchi, R. A. (ed.). Holos, Ribeirão Preto.

Santos, P., Uramoto K.\& Matioli, S.R. 2001. Experimental hybridization among Anastrepha species (Diptera: Tephritidae): production and morphological characterization of $F_{1}$ hybrids. Annals of Entomological Society of America 94:717-725.

Selivon, D. 1996. Estudo sobre a diferenciação populacional em Anastrepha fraterculus (Wiedemann) (Diptera: Tephritidae). Tese de Doutorado. Depto de Biologia, Instituto de Biociências, Universidade de São Paulo, SP.

Selivon, D. \& Perondini, A.L. 2000. Morfologia dos ovos de moscas-das-frutas do gênero Anastrepha. p. 49-54. Em: "Moscas-das-frutas de Importância Econômica no Brasil: Conhecimento Básico e Aplicado". Malavasi, A. \& Zucchi, R. A. (ed.). Holos, Ribeirão Preto.

Selivon, D. \& Perondini, A.L.P. 2007. Especies crípticas Del complejo Anatrepha fraterculus en Brasil. p.101-118. Em: "Moscas de La Fruta em Latinoamérica (Diptera: Tephritidae): Diversidad, biologia y manejo". Henández-Ortiz (ed). S y G editores, Distrito Federal, México.

Selivon, D.; Perondini, A.L.P. \& Morgante, J.S. 1999. Haldane's rule and other aspects of reproductive isolation observed in the Anastrepha fraterculus complex (Diptera: Tephritidae). Genetics and Molecular Biology 22: 507510.

Selivon, D.; Perondini A.L.P.; Goday, C.; Sánchez, L.; Ruiz, M.F. 2004 Caracterização de regiões heterocromáticas dos cromossomos mitóticos e do DNA ribossômico de espécies de Anastrepha (Diptera: Tephritidae). 50 Congresso Nacional de Genética. Florianópolis (CD do congresso)..

Selivon, D; Vretos, C.; Fontes, L.; Perondini, A.L.P. 2004b. New variant forms in the Anastrepha fraterculus complex. p.253-258. Proceedings of. $6^{\text {th }}$ 
International Fruit Flies Symposium, 6-10 May, Stellenbosh, South Africa, B. Barne 9ed.), Isteg Scientific Publications, Irene, Africa do Sul.

Selivon, D.; Perondini, A.L.P.; Ribeiro, A.F.; Marino, C.L.; Lima, M.M.A. \& Coscrato, V.E. 2002. Wolbachia endosymbiont in a species of the Anastrepha fraterculus complex (Diptera, Tephritidae). Invertebrate Reproduction and Development 42: 121-127.

Selivon, D.; Perondini, A. L. P.; Morgante, J.S. 2005. A genetic-morphological characterization of two cryptic species of the Anastrepha fraterculus complex (Diptera, Tephritidae). Annals of the Entomological Society of America: 98(3): 367-381.

Sinkins, S.P.; Braig, H.R. \& O’Neill, S.L. 1995. Wolbachia pipientis: Bacterial density and unidirectional cytoplasmic incompatibility between infected populations of Aedes albopictus. Experimental Parasitology 81: 285-291.

Smith-Caldas, M.R.B.; McPheron, B.A.; Silva, J.G.; Zucchi, R.A. 2001. Phylogenetic relationships among species of the fraterculus group (Anastrepha: Diptera: Tephritidae) inferred from DNA sequences of mitochondrial cytochrome oxidase I. Neotropical Entomology 30: 565-573.

Stone, A. 1942. The fruit flies of the genus Anastrepha. U.S. Dep. of Agric., Miscellaneous Publication 439: 1-112.

Sun, X.; Cui, L. \& Li, Z. 2007. Diversity and Phylogeny of Wolbachia Infecting Bactrocera dorsalis (Diptera: Tephritidae) Populations from China. Environmental Entomology 36(5): 1283-1289.

Telschow, A.; Hammerstein, P. \& Werren, J.H. 2005a. The effect of Wolbachia versus genetic incompatibilities on reinforcement and speciation. Evolution 59: 1607-1619.

Telschow, A.; Yamamura, Y. \& Werren, J.H. 2005b. Bidirectional cytoplasmic incompatibility and the stable coexistence of two Wolbachia strains in parapatric host populations. Journal of Theoretical Biology. 235: 265-274.

Tram U. \& Sullivan, W., 2002. Role of delayed nuclear envelope breakdown and mitosis in Wolbachia-induced cytoplasmic incompatibility. Science 296: 1124-1126.

Turelli, M. 1994. Evolution of incompatibility inducing microbes and their hosts. Evolution 48: 1500-1513.

Turelli, M. 2000. The Causes of Haldane's Rule. Science 282: 889-891. 
Weeks, A.R. \& Breeuwer, J. A.J. 2003. A New Bacterium from the CytophagaFlavobacterium-Bacteroides Phylum That Causes Sex-Ratio Distortion. p. 165-176. Em: "Insect Symbiosis". Bourtzis, K. \& Miller, T. A. (ed.). CRC Press. Boca Raton, Florida.

Werren, J.H. 1997. Biology of Wolbachia. Annu. Rev. Entomol. 42: 587-609.

Werren, J.H. 1998. Wolbachia and Speciation. p. 245-260. Em: "Endless forms: species and speciation", Howard, D.; Berlocher, S. (eds.), Oxford University Press, Oxford.

Werren, J.H; O'Neill, S.L 1997 The evolution of heritable symbionts. . p.1-41 Em: "Influential passengers: Inherited microorganisms and arthropod reproduction", O'Neill, S.L.; Hoffmann, A.A.; Werren J.H. (ed.). Oxford: Oxford University Press. p.1-41.

Werren, J.H.; Windsor, D. \& Guo, L.R. 1995. Distribution of Wolbachia among neotropical arthropods. Proc. Royal Soc. London B. 262:197-204.

Werren, J.H. \& Windsor, D.M. 2000. Wolbachia infection frequencies in insects: evidence of a global equilibrium? Proc. R. Soc. Lond. B 267: 1127-1285.

White, I.M.; Elson-Harris, M.M. 1992. Fruit flies of economic significance: their identification and bionomics. CAB International, Wallinford, UK.

Wieschaus, E. \& Nüsslein-Volhard, C. 1986. Looking at embryos. Em: Drosophila: a practical approach. IRL Press, Oxford.

Wright, J.D. \& Wang, B.-T. 1980. Observation on Wolbachia in mosquitoes. J Invertebr Pathol 22: 242-250.

Yen, J.H. \& Barr, A.R. 1974. Incompatibility in Culex pipiens. p. 97-118. Em : "The Use of Genetics in Insect control. Pal, R. \& Whitten, M.J. (eds). Elsevier North-Holland, Amsterdam.

Zabalou, S.; Riegler, M.; Theodorakopoulou, M.; Stauffer, C.; Savakis, C. \& Bourtzis. K. 2004. Wolbachia-induced cytoplasmic incompatibility as a means for insect pest population control. Proceedings. National. Academy of Science of USA 101: 15042-15045.

Zhou, W.; Rousset, F. \& O’Neill, S. 1998. Phylogeny and PCR-based classification of Wolbachia strains using wsp gene sequences. Proceedings Royal Society of London B 265: 509-515.

Zucchi, R.A. 2007. Diversidad, Distribución y Hospederos del Género Anastrepha em Brasil. Em: Hernándes-Ortiz, V. (Ed.). Moscas de La fruta 
em Latinoamérica (Diptera: Tephritidae): diversidade, biologia y manejo. S y $\mathrm{G}$ editores, Distrito Federal. 


\begin{tabular}{|c|c|c|c|c|c|c|c|}
\hline$\frac{5}{6}$ & 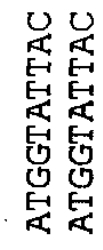 & 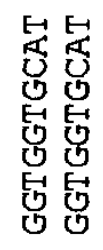 & 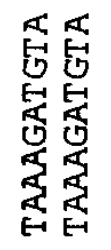 & 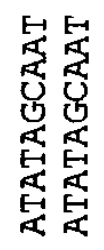 & 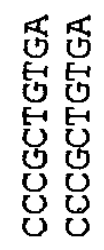 & 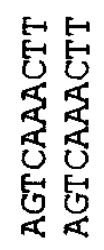 & 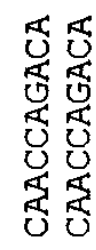 \\
\hline $\begin{array}{l}0 \\
0 \\
\frac{0}{9} \\
\frac{9}{0}\end{array}$ & 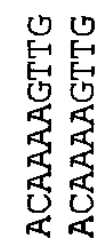 & 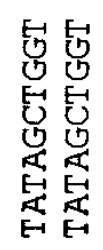 & 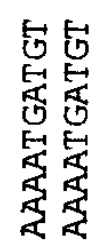 & 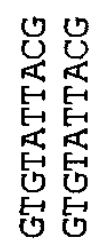 & 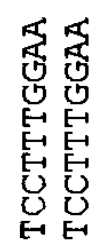 & 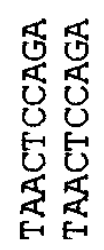 & 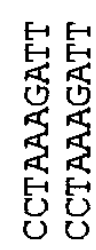 \\
\hline $\begin{array}{l}\dot{1} \\
0 \\
0 \\
0 \\
3\end{array}$ & 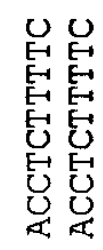 & 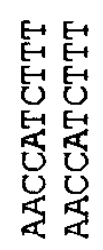 & 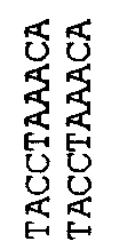 & 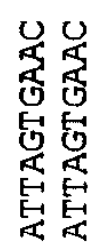 & 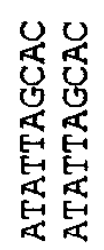 & 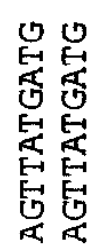 & 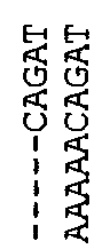 \\
\hline $\begin{array}{l}\frac{\Phi}{5} \\
0 \\
0 \\
0\end{array}$ & 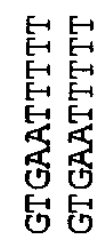 & 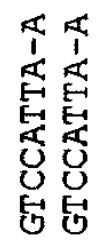 & 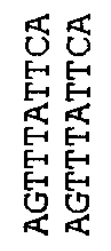 & 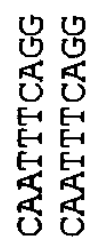 & 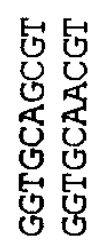 & 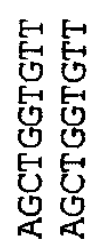 & 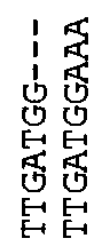 \\
\hline $\begin{array}{l}\mathscr{0} \\
\bar{E} \\
\mathscr{D} \\
\frac{5}{\delta} \\
\mathcal{O}\end{array}$ & 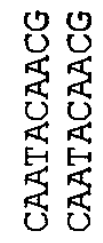 & 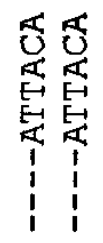 & 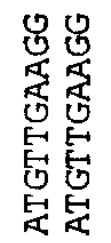 & 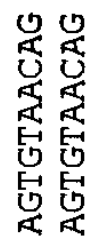 & 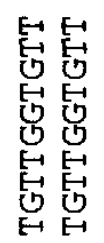 & 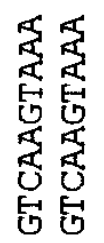 & 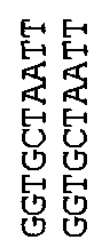 \\
\hline 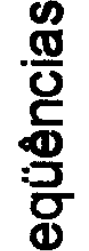 & 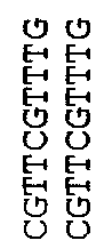 & $\begin{array}{l:}1 \\
1 \\
1 \\
1 \\
1\end{array}$ & 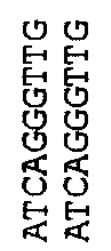 & 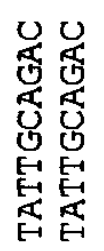 & 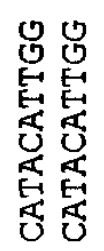 & 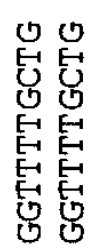 & 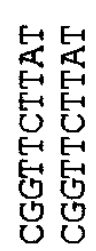 \\
\hline$\frac{c}{c}$ & 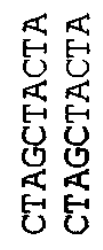 & 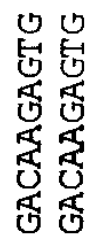 & 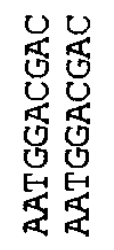 & 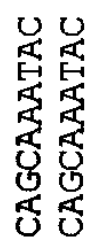 & 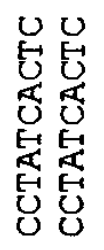 & 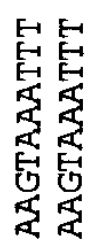 & 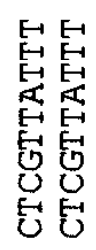 \\
\hline 8 & 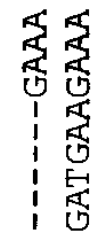 & 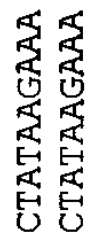 & 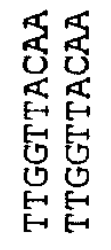 & 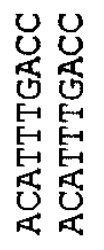 & 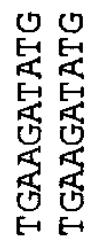 & 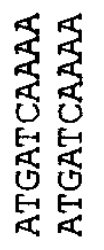 & 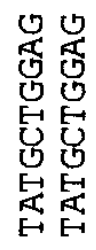 \\
\hline & 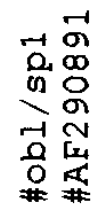 & 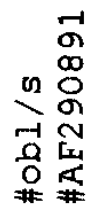 & 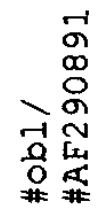 & 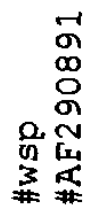 & 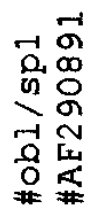 & 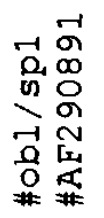 & 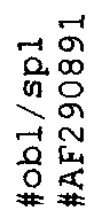 \\
\hline
\end{tabular}

